\title{
Atmospheric Phenomena, Energetic Electrons, and the Geomagnetic Field ${ }^{1,2}$
}

\author{
J. R. Winckler \\ Contribution from School of Physics, University of Minnesota, Minneapolis 14, Minn.
}

(Received October 17, 1961)

\begin{abstract}
This paper discusses X-ray measurements associated with the dumping of electrons from the magnetic field, made with balloons and rockets. It is shown that in the normal auroral zone the X-ray bursts occur throughout the 24-hour period, have peak intensities corresponding to electron fluxes of $10^{6}$ to $10^{7} / \mathrm{cm}^{2} \cdot \mathrm{sec}$, and have integrated fluxes over a $24-$ hour period of $10^{10} / \mathrm{cm}^{2}$. In the auroral zone the X-ray bursts arising from $30-\mathrm{kv}$ or higher electrons are not correlated with visible aurorae. Direct rocket measurements of bright aurorae in the auroral zone confirm this by showing the absence of appreciable electron fluxes above $20 \mathrm{kv}$. At lower latitudes, however, the X-rays are well-correlated with visible aurorae, have peak burst intensities of $10^{3}$ electrons $/ \mathrm{cm}^{2} \cdot \mathrm{sec}$ greater than $30 \mathrm{kv}$, and are also strongly correlated with negative bays in the local magnetic field. The Van Allen outer radiation belt electrons provide a suitable reservoir for explaining many characteristies of the X-rays because of the latitude distribution and energy of the trapped radiation. Acceleration, deceleration, and redistribution processes are suggested which may result in the precipitation of these electrons to form the X-rays.
\end{abstract}

\section{Introduction}

In the last several years a considerable number of measurements have been made of bremsstrahlung detected at balloon altitudes and originating from energetic electrons incident on the high atmosphere. Because these measurements may have an important relationship to the processes in the ionosphere, the magnetic field of the earth and its trapped radiation, and the sun, certain features which are emerging in the analysis of these data seem worthy of discussion.

It appears that the electrons responsible for balloon $\mathrm{X}$-ray events have an energy spectrum much like the Van Allen outer zone electrons, and that the peak intensity of the bursts at different latitudes follows the intensity of outer zone trapped electrons projected to the surface of the earth along lines of force. It is possible that low-latitude aurorae may be largely due to these electrons, but it now seems certain that the classical polar aurora is not so associated, and that it consists almost entirely of very low energy electrons. These low energy particles are precipitated into the auroral zone from a region in the magnetic field at 6 to 10 earth radii. This region and the low energy particles which populate it (not measured by previous satellites or probes) may be the seat of the ring currents assumed responsible for the main phase of magnetic storms, and for the alteration of the Störmer cutoff energies for cosmic rays.

We shall not be concerned here with the origin of the polar aurora, but rather will examine the evidence for the energetic X-ray electrons, and consider mechanisms by which they may be precipitated by

\footnotetext{
1 This work was supported by the Office of Naval Research, the National Aeronautics and Space Administration, and the National Science Foundation.

2 A portion of this material was presented at the URSI Symposium on Physical Processes in the Earth's Plasma Environment, May 1,1961, at Washington, D.C.
}

acceleration, deceleration, or scattering of the outer radiation belt electrons.

The balloon measurements come from the work of three groups: Anderson and co-workers at the State University of lowa, Brown and co-workers at the University of California, and Winckler and coworkers at the University of Minnesota. Balloon measurements have been carried out at three locations, namely Ft. Churchill, Manitoba, Canada; Fairbanks, Alaska; and Minneapolis, Minnesota. In addition, the detection of bremsstrahlung radiation by Van Allen and co-workers with rockoon flights above the atmosphere in 1954 and 1955 and recent rocket measurements in visible aurorae by McIlwain and in high latitude X-ray events by Davis have very important bearing on the interpretation of these data.

The X-rays have come to be known as auroral $\mathrm{X}$-rays, although this is certainly not correct in certain respects, as will be discussed below. Although the geographical coverage of the data is meager and the balloon observations, compared with other geophysical observations, are infrequent, these measurements have the great advantage over many geophysical data that they are a well-defined physical quantity and lead to specific knowledge about the spectrum, energy, and time variations of the electrons incident on the top of the atmosphere. With such knowledge about the properties of the incident electrons on the atmosphere, the real problems begin concerning their origin, their mechanism of discharge from the magnetic field, their relationship to the Van Allen belts, changes in the magnetic field, and solar influences.

A close association exists between the balloon Xray events and the increase of density of ionospheric $D$-layer electrons. This results in the increased 
absorption of radio waves in this region as shown by riometers. The complete analysis of this problem is complex and we shall attempt only to give some typical data in this paper.

In an examination of the X-ray data it is apparent that the measurements in the auroral zone have different time behavior and associations than the X-ray measurements at lower latitude, and that these differences seem to have a relationship to the properties of trapped radiation measured by earth satellites and rockets in the magnetic field of the earth. We will therefore divide our discussion between the characteristics of the X-rays seen in the auroral zone and those seen at lower latitudes.

In the balloon measurements, the X-rays are detected with steel and aluminum ion chambers, various types of Geiger counter configurations, and scintillation counters. Each of these instruments has a definite sensitivity for photons of various energies which can be quite well determined. The scintillation counters are the most sensitive, and the aluminum ionization chambers and thin wall Geiger counters, especially those shielded from background cosmic radiation, also have a relatively high sensitivity. Single Geiger counters can detect the stronger events, but are hampered by absorption in the counter walls and the large background in the atmosphere of charged particles from the cosmic radiation. The measurements are commonly made at an atmospheric height of 30 to $40 \mathrm{~km}$, which corresponds to about 5 to $10 \mathrm{~g} / \mathrm{cm}^{2}$ of air between the balloon and the source of the bremsstrahlung. The bremsstrahlung is produced in a layer where the primary electrons come to rest at a height of about 80 to $100 \mathrm{~km}$. Between that height and the balloon the photons are absorbed in an energy-dependent manner, mainly by the photoelectric process, but attenuation and degradation also occur by Thompson and Compton-type scattering.

\section{Low Latitude X-Ray Bursts}

We shall begin with a discussion of the X-ravs as observed at Minneapolis, Minn., at a latitude of about $55^{\circ}$ geomagnetic. The Minneapolis observations of X-rays always occur during considerable disturbances of the earth's magnetic field and, wherever visual observations can be made, are found to accompany strong aurorae at the zenith at the time of the observation of the bremsstrahlung. This was true in the very first case so measured, on July 1, 1957, when the aurora was well observed visually. Subsequent cases were also observed visually and with all-sky cameras located at nearby points. One of the most striking cases was the great storm of September 23, 1957. We show, in figures 1 and 2, the balloon X-ray bursts measured by the IGY-type steel ionization chamber and the brass Geiger counter, both relatively insensitive instruments, and, for comparison, all-sky camera records from Choteau, Mont. The timing of the X-ray-produced rate increases with strong features of the visual aurora is within approximately $1 \mathrm{~min}$. In this case a very long rayed arc stretching across much of the northwestern United States was present [Winckler, 1960]. This means that the origin of the $\mathrm{X}$-rays was within $\pm 50 \mathrm{~km}$ of the zenith where the auroral forms were observed. Thus it cannot be stated with exact certainty that the electrons producing the bremsstrahlung were a part of the individual rayed structures, as these are generally less than $1 \mathrm{~km}$ in lateral extent. However, the limit given above is consistent with the absorption of X-rays in the atmosphere so that X-rays from greater distances than $50 \mathrm{~km}$ would not be detected.

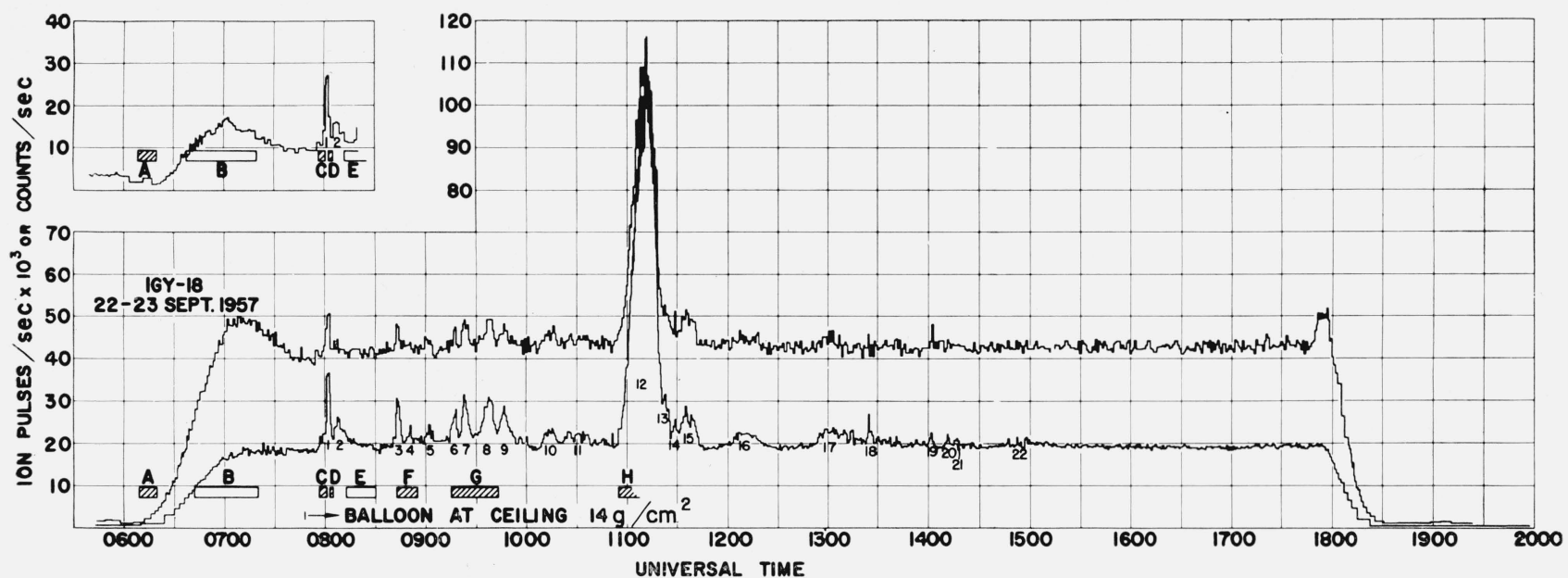

FIGURE 1.-Ion chamber (bottom), single counter (top), and photon counter (upper left, separate curve) response during the intense auroral storm of September 2.2-23, $195 \%$.

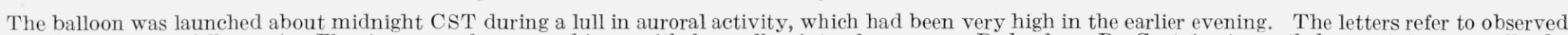

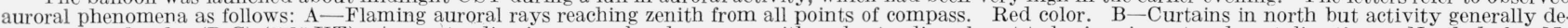

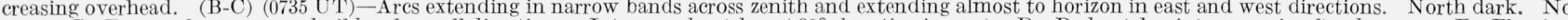

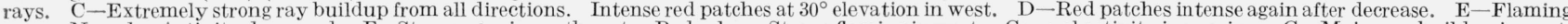

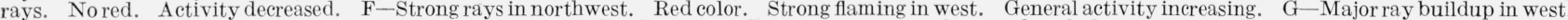

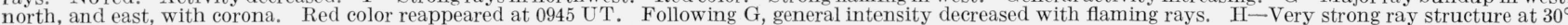
elevation in east with intense red color. Visible against predawn sky light. 

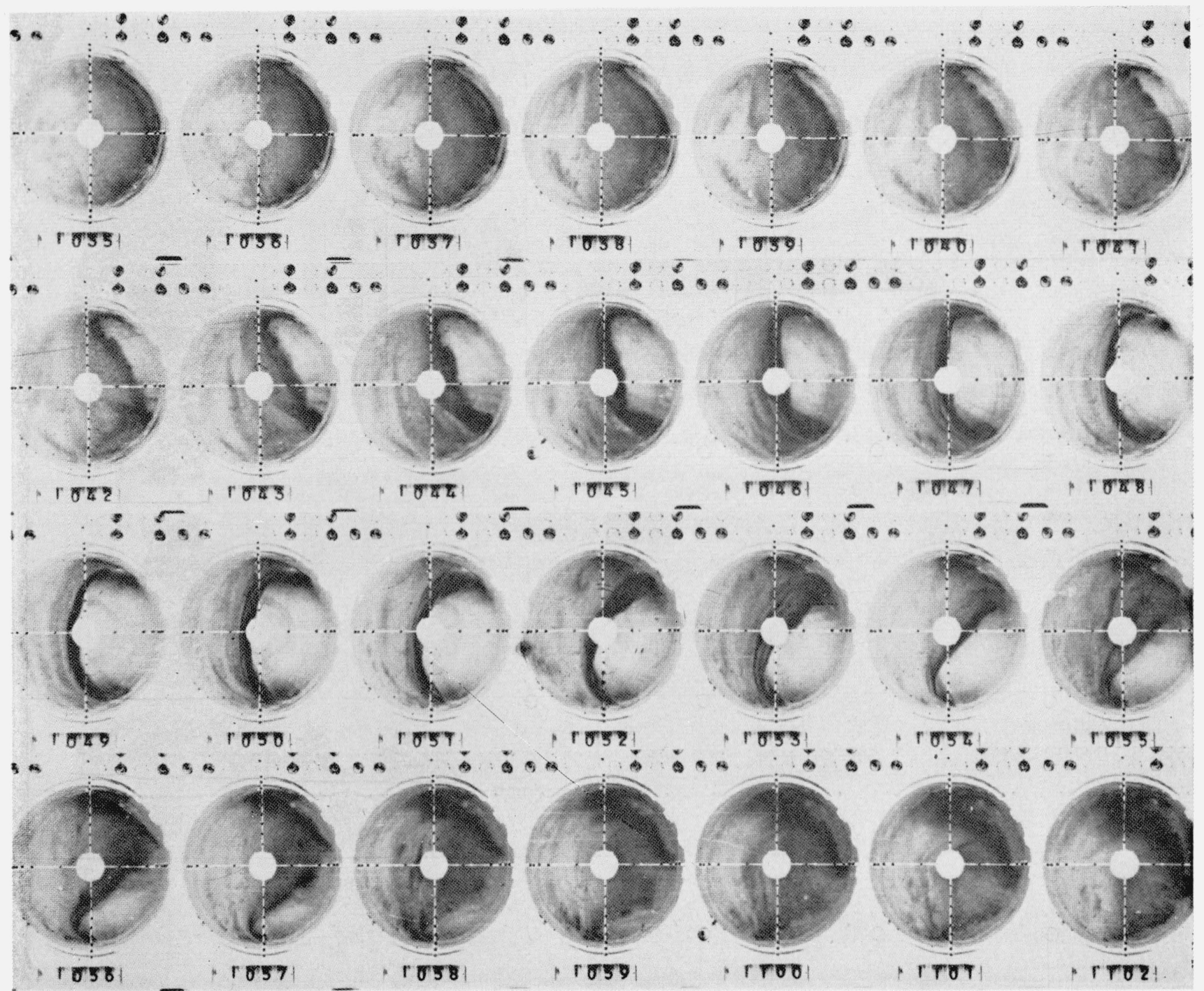

Figure 2. Auroral all-sky camera records from Choteau, Montana, on September 23, $195 \%$.

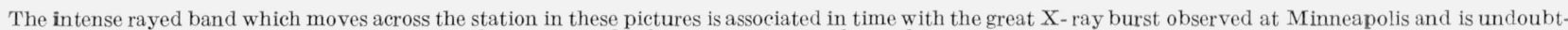
edly a part of the same auroral feature, which existed over a considerable range of longitudes at this time.

It thus appears that the electrons are localized in a region near the rayed or active structures of the low latitude aurorae. The cases of auroral-associated X-ray bursts measured at Minneapolis have been summarized for the IGY in a recent paper [Winckler, 1960]. Many other observations were made during 1959 and 1960. Some of these have been studied and reported in the literature [Winckler, Bhavsar, 1960; Winckler, Bhavsar, Peterson, 1961]. In some of the very strongest storms the X-rays were accompanied by solar cosmic ray particles. In such cases the photons could be measured only with special instruments such as scintillation counters which would respond selectively to the $\mathrm{X}$-rays and not to the cosmic ray particles.

A recent study has been made covering the period August 23, 1959 to August 29, 1960 [May, 1961]. During this period cases of X-ray bursts were studied and correlated with the total magnetic field of the earth measured with a rubidium vapor magnetometer at Minneapolis. A summary of these events is given in table 1. The tabulation shows the duration of the event, the intensity of the X-rays measured in terms of the response of the standardized ion chamber the estimated mean energy, and the total flux of electrons striking the top of the atmosphere which corresponds to the observed photons at balloon heights. Figures 3, 4, and 5 are examples of the $\mathrm{X}$-ray bursts observed during this period compared with the total field magnetometer. These figures show very clearly the strong association between negative excursions from normal of the magnetic field and the precipitation of electrons on the high atmosphere. Examination of the records also shows the nighttime character of the events. In the $1-\mathrm{yr}$ period from August 1959 to August 1960, 8,050 hrs 
Table 1. Summary of X-ray events between 2O August 1959 and 1 August 1960

\begin{tabular}{|c|c|c|c|c|c|c|c|c|c|}
\hline (1) & (2) & (3) & (4) & (5) & $(6)$ & \multicolumn{3}{|c|}{ (7) } & $(8)$ \\
\hline \multirow{2}{*}{$\begin{array}{l}\text { Date } \\
\text { (UT) }\end{array}$} & \multirow[b]{2}{*}{ Flight } & \multirow{2}{*}{$\begin{array}{l}\text { Time } \\
\text { (UT) }\end{array}$} & \multirow{2}{*}{$\begin{array}{l}\text { Peak ion } \\
\text { chamber } \\
\text { intensity } \\
\text { (normalized } \\
\text { pulses/sec) }\end{array}$} & \multirow{2}{*}{$\begin{array}{l}\text { Total No. } \\
\text { of electrons } \\
\mathrm{cm}^{2}\end{array}$} & \multirow{2}{*}{$\begin{array}{l}\text { Approx. } \\
\text { time of } \\
\text { burst } \\
\text { (min) }\end{array}$} & \multicolumn{3}{|c|}{ Ratio of rates } & \multirow{2}{*}{$\begin{array}{c}\text { Energy } \\
\text { (kev) }\end{array}$} \\
\hline & & & & & & $\frac{\mathrm{IC}}{\mathrm{Cu}}$ & $\frac{\mathrm{IC}}{\mathrm{Al}}$ & $\frac{\mathrm{Al}}{\mathrm{Cu}}$ & \\
\hline 23 Aug. 59 & M-3 & 0850 & 0.002 & $2 \times 10^{9}$ & 95 & & & & \\
\hline 2 Oct. 59 & M-6 & 0430 & .043 & $3 \times 10^{9}$ & 35 & 0.010 & 0.0070 & 1. 6 & 64 \\
\hline 4 Oct. 59 & M-7 & (1) 0430 & .082 & $5 \times 10^{10}$ & 110 & .024 & .0114 & 2.1 & 51 \\
\hline 3 Dec. 59 & $\mathrm{M}-14$ & $\begin{array}{r}\text { (2) } 0750 \\
0800\end{array}$ & .022 & $2 \times 10^{10}$ & $\begin{array}{l}110 \\
190\end{array}$ & .019 & .0091 & 2.1 & 52 \\
\hline 11 Jan. 60 & M-18 & 0900 & .004 & $3 \times 10^{9}$ & $\begin{array}{r}190 \\
50\end{array}$ & & & & \\
\hline 1 A pr. 60 & M- -37 & 0345 & .005 & $1 \times 10^{9}$ & 30 & & .0092 & & 54 \\
\hline 2 A pr. 69 & $\mathrm{M}-41$ & 0420 & .007 & $2 \times 10^{10}$ & 185 & .010 & .0062 & 1.6 & 64 \\
\hline & $\mathrm{M}$ & 1050 & .020 & $5 \times 10^{10}$ & 215 & .025 & .0093 & 2.7 & 55 \\
\hline 3 Apr. 60 & M-43 & 0600 & .076 & $2 \times 10^{11}$ & 200 & .026 & .0095 & 2.7 & 5 \\
\hline $29 \mathrm{Apr} .60$ & M-53 & 0640 & .295 & $2 \times 10^{11}$ & 85 & .028 & .0109 & 2.7 & 53 \\
\hline 30 Apr. 60 & M-54 & 0200 & .011 & $2 \times 10^{10}$ & 130 & .008 & .0064 & 1.2 & 69 \\
\hline & $\begin{array}{l}\mathrm{M}-55 \\
\mathrm{M}-56\end{array}$ & $\begin{array}{l}0620 \\
1840\end{array}$ & 01 & & 370 & & & 2.3 & $\begin{array}{l}56 \\
55\end{array}$ \\
\hline 7 May 60 & M-63 & $\begin{array}{l}1840 \\
0510\end{array}$ & $\begin{array}{l}.012 \\
.113\end{array}$ & $\begin{array}{l}2 \times 10^{10} \\
1 \times 10^{11}\end{array}$ & $\begin{array}{l}390 \\
245\end{array}$ & $\begin{array}{r}.024 \\
023\end{array}$ & .0103 & $\begin{array}{l}2.3 \\
2.1\end{array}$ & $\begin{array}{l}55 \\
55\end{array}$ \\
\hline 11 May 60 & $\mathrm{M}-67$ & 0630 & .003 & $3 \times 10^{9}$ & $\begin{array}{r}2+J \\
85\end{array}$ & & & & \\
\hline 5 June 60 & $M-75$ & 0930 & .019 & $1 \times 10^{10}$ & 75 & & .0074 & (n) & 62 \\
\hline
\end{tabular}

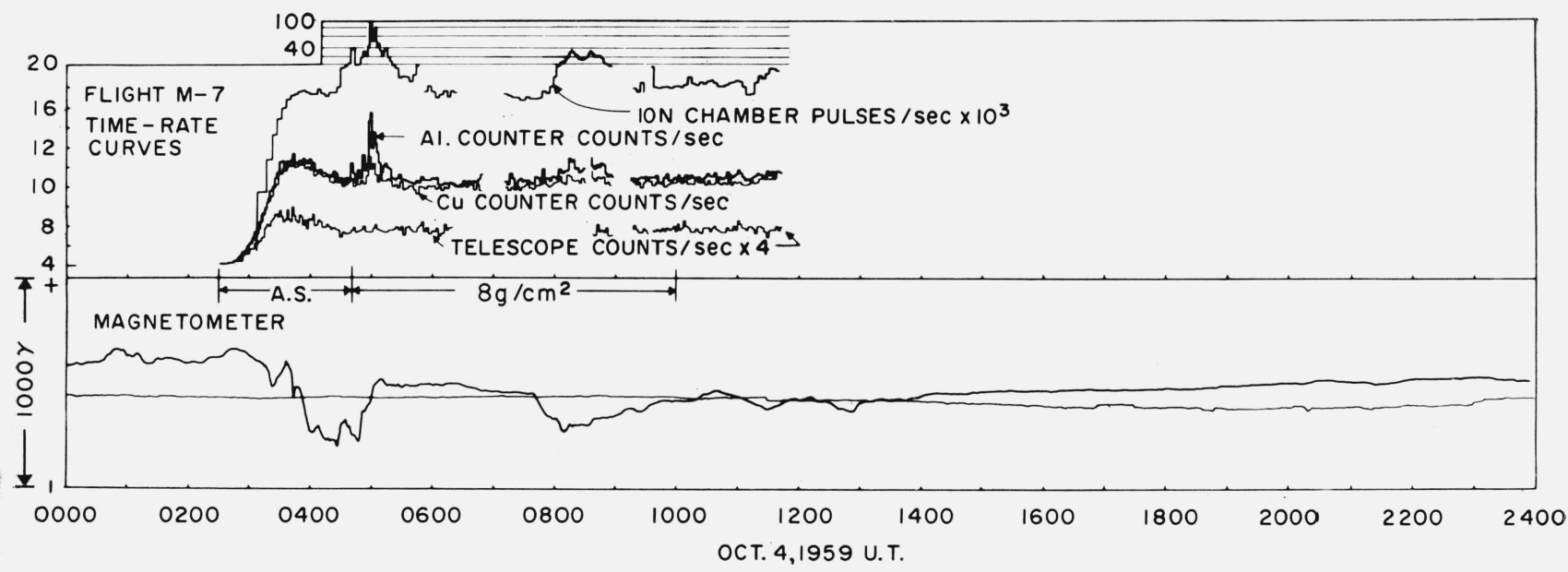

FIGURE 3. Rates of balloon detectors at high altitude (upper) and local total field magnetometer (lower).

The balloon arrived at ceiling in the middle of the first negative excursion of the magnetometer. After the balloon arrived at ceiling, the X-ray burst shows a very detailed correlation with the negative excursions of the magnetic field. There is a positive excursion of the magnetic field before the auroralevents. Note absence of response on telescope, showing that the event is due to photons. (From T.C. May [1961].)

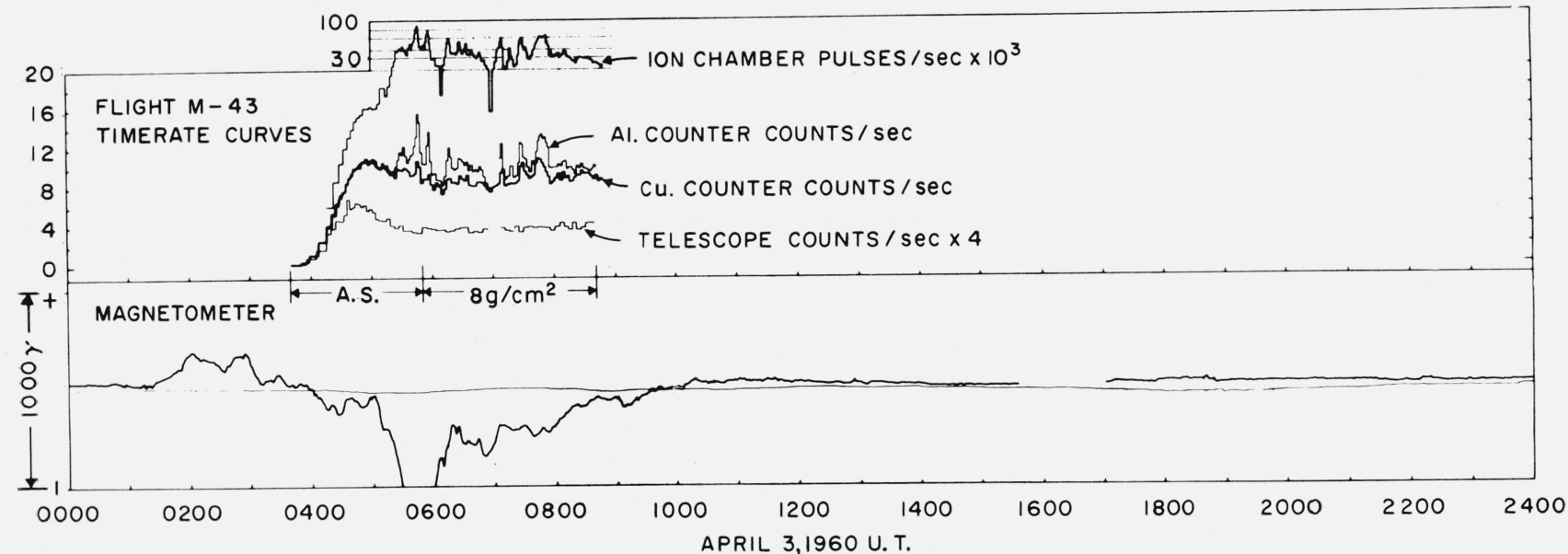

Figure 4. A large X-ray event observed at high altitude during the A pril 1960 magnetic storm.

Note appearance of X-rays during negative phase. (From T.C. May [1961].) 


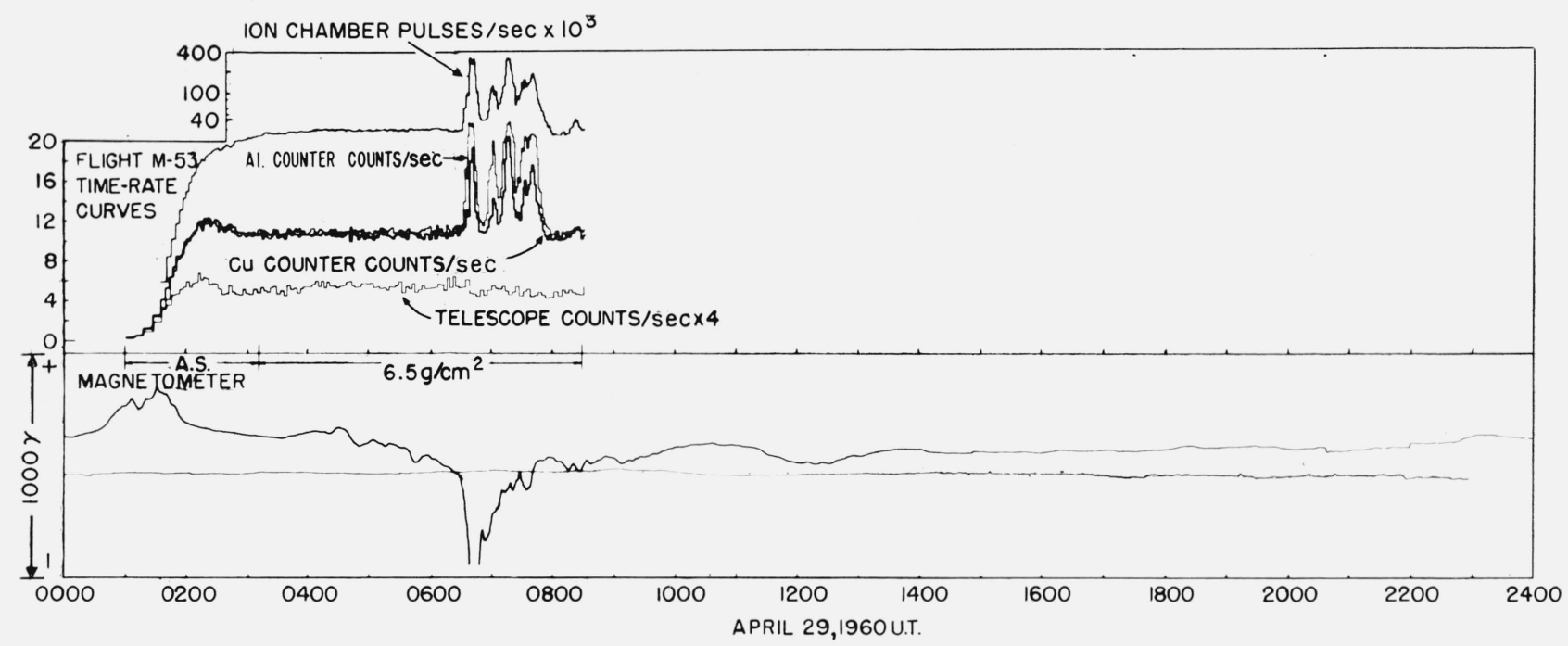

FIgure 5. This X-ray event is superimposed on a high energy solar cosmic ray event

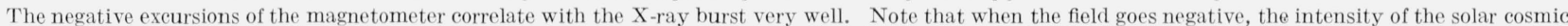

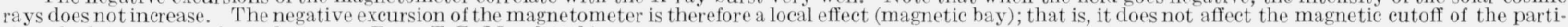
rays does not increase. The negative excursion of the magnetom
cles which are coming from the sun. (From T.C. May [1961].)

of magnetic records were taken at Minneapolis. Considering all events in which the magnetometer excursion was greater than $100 \gamma$ negative, the total number of hours is 134. Eighty-three percent of these were in the 12 hrs centered at local midnight. Of the 134 disturbed hours, $38.5 \mathrm{hr}$ were covered by balloons floating at ceiling altitude at Minneapolis, with instruments in proper operation. X-ray bursts were observed 64 percent of the time. On the other hand, 447 hrs of balloon flight at ceiling with instruments operating properly were obtained during quiet periods with the magnetic field deviating less than $100 \gamma$ negative and X-rays were observed only 1 percent of the time.

A strong correlation has been shown to exist between magnetic bays and aurorae [Bless, Gartlein, Kimball, and Sprague, 1959]. This association, coupled with visual observations which have been made from time to time, provides convincing evidence that the whole phenomenon at $\gamma=55^{\circ}$ occurs simultaneously, namely, the presence of visible aurora, strong negative excursions of the magnetic field, and the precipitation of electrons from the magnetic field into the atmosphere. The magnetic storms which produce aurorae at $55^{\circ}$ geomagnetic latitude at the zenith are mainly the large storms of the period of solar maximum. The aurora, Xrays, and other associated events occur during the main phase of such storms. Since the storm time magnetic field has a systematic worldwide character, and is not dependent on local time, the effects mentioned above which are highly concentrated in the dark hours may be considered to be nighttime intensifications of the phenomena which occur during the main phase. It is well known that the main phase contains many local large variations which differ from one longitude to another. Apparently the local time effect refers to these superposed deviations during the main phase which are not worldwide in character.
Figure 6 shows a further measurement, this time with a scintillation counter, of X-ray bursts at Minneapolis accompanying a series of magnetic bays during a storm on July 16, 1960. Several interesting features are shown by the scintillation counter which are not detected by the ion chambers. First, the very short time scale of the X-ray fluctuations is shown, as bursts are observed down to the limit of time resolution of the scintillation counter which lies in the range of a few seconds. Such rapid fluctuation can only be due to the irregular manner in which the electrons are precipitated on the atmosphere. Second, the steeply rising photon intensity, as measurements are made at lower and lower energies, is also apparent by comparing the low energy and high energy channels in figure 6 .

It is well, at this point, to consider the problem of inferring from the observed bremsstrahlung intensity and spectrum at balloon heights the flux and spectrum of the electrons incident on the top of the atmosphere. This interpretation involves knowledge of the processes in the "thick target" conversion of electrons to bremsstrahlung in the atmosphere, the processes of absorption of this thick target spectrum as the photons proceed down to balloon altitudes, and the relative sensitivity of the instruments in the different regions of the bremsstrahlung spectra. Possible solutions of this interpretive problem have been obtained by careful calculation of all the various steps in the process from theoretical and empirical information. Since such a procedure is complex and is frequently criticized, a direct experimental check on the entire process has also been carried out by the specially constructed laboratory X-ray generator shown in figure 7 . This machine is a small accelerator working in the range 20 to $100 \mathrm{kv}$, and a known current of electrons can be made to bombard an aluminum target on the end of the accelerating tube. Experimental apparatus can be placed below this target. In this way 

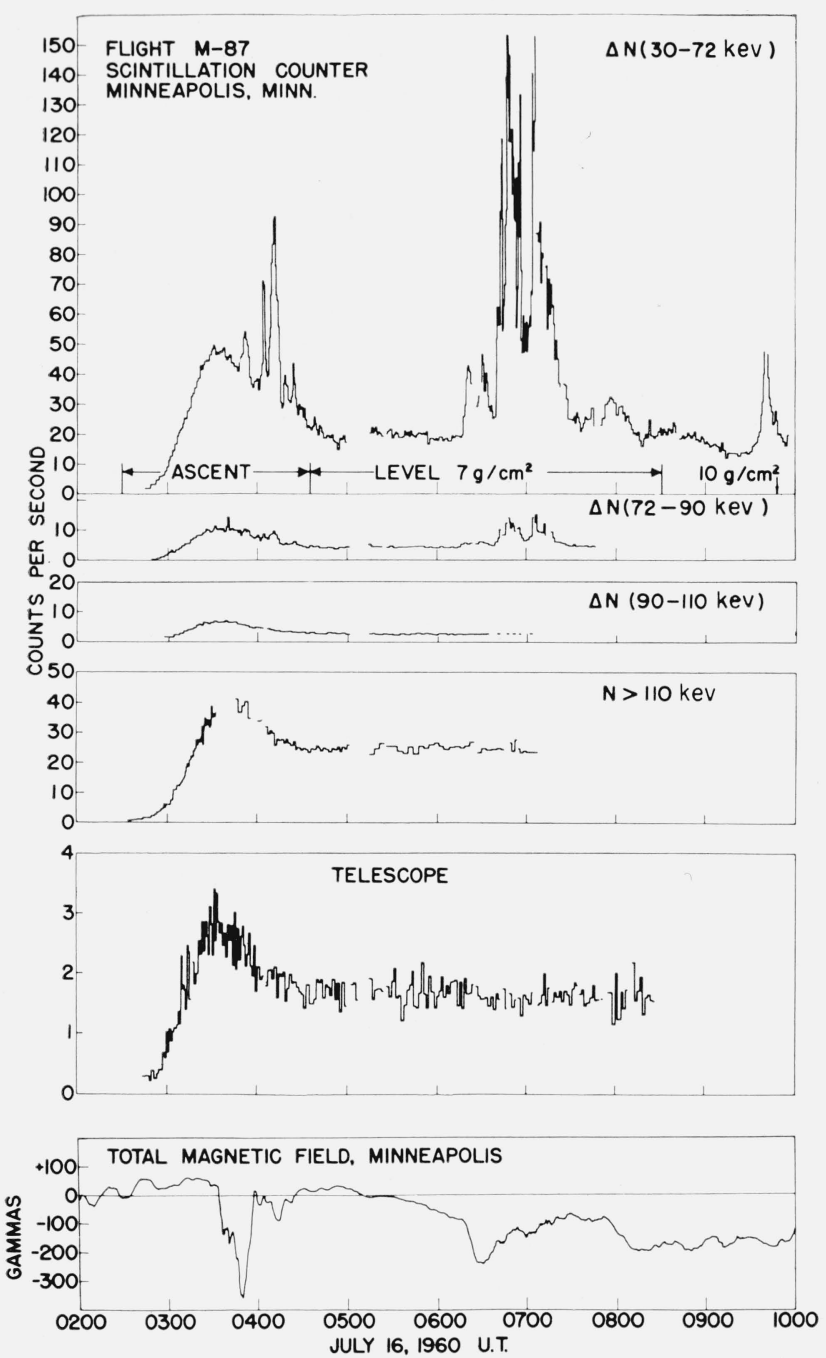

FIgURE 6. Scintillation counter record of an X-ray event measured at Minneapolis.

Note the concentration of photons in the low energy channels and the correspondence to negative excursions of the total field magnetometer.

the theoretically expected bremsstrahlung response of the ion chambers and counters was compared directly with the measured values [May, 1961]. The theoretical data for the thick target bremsstrahlung spectra in air were obtained from the work of Casper (State University of Iowa, private communication). These curves give the photon spectrum radiated by monoenergetic electrons which slow down and lose energy mainly by ionization in the atmosphere, and at each energy in the slowing down process radiate the appropriate quanta due to the bremsstrahlung process. Correction was made for the aluminum-to-air dependence of bremsstrahlung production in the electron target and the response of the ion chambers and counters was calculated from the known atomic processes involved in the absorption of the X-rays of various energies. In this way the ionization chamber pulsing rate and the Geiger counter counting rate were computed for a normalized flux of electrons of each energy.

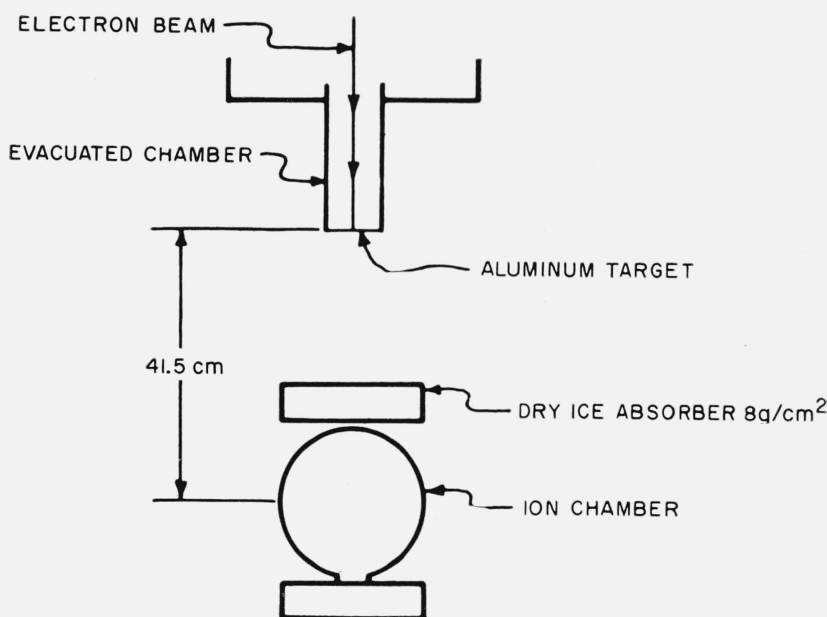

FiguRE 7. Laboratory simulation of atmospheric $X$-ray processes.

The unit shown is the standard balloon monitoring unit but measurements have also been made using scintillation counters.

These calculated results agree extremely well with the laboratory measurements where the entire situation was simulated with the X-ray accelerator. A block of dry ice was used to simulate the atmosphere above the balloon. A comparison at two typical energies is given in table 2 , between the theoretical and experimental results. The standard monitoring instruments like the ionization chamber and Geiger counter can, of course, only give a mean energy for any measured spectrum. Various trial spectra for the electrons incident on the atmosphere can be put into the process and the ratios of the response of the instruments can be determined. This can then be compared with the measured ratio for estimating the probable type of spectrum and the electron flux. Such results are summarized in the columns of table 1 . From the scintillation counter, on the other hand, spectral information is obtained about the photons. Then the trial electron spectra, when converted to photons, can be compared with the experimental curves much more precisely. In principle, for bremsstrahlung observations it is impossible to infer in a completely unambiguous manner the electron spectrum from the observed photon spectrum in the atmosphere. However, the method of "trial" electron spectra gives useful results and is consistent with the present state of knowledge of the entire subject. Such a calculation has been carried out for the aurora of May 12, 1959 by Bhavsar [1961]. Typical results of this are given in figure 8. An electron spectrum represented by the following power law relation fits the observed values at the low er energies:

$$
N(>E)=0.66 \times 10^{15} E^{-5}
$$

with $E$ in kilovolts, the spectrum representing an average over an 80-min burst. This power law spectrum is similar to that estimated for the outer zone of the Van Allen trapped radiation [Vernov and Chudakov, 1960]. At higher energies the observed photon spectrum flattens more than can be produced 
TABLE 2. Experiments and calculated chamber response to $d$-c X-ray machine

\begin{tabular}{c|c|c}
\hline \hline $\begin{array}{c}\text { Electron energy } \\
\text { (kev) }\end{array}$ & $\begin{array}{c}\text { Experimental response } \\
\text { (pulses/electron) }\end{array}$ & $\begin{array}{c}\text { Calculated response } \\
\text { (pulses/electron) }\end{array}$ \\
\hline 50 & $2.2 \times 10^{-13}$ & $\begin{array}{c}2.1 \times 10^{-13} \\
9.7 \times 10^{-13}\end{array}$ \\
\hline
\end{tabular}

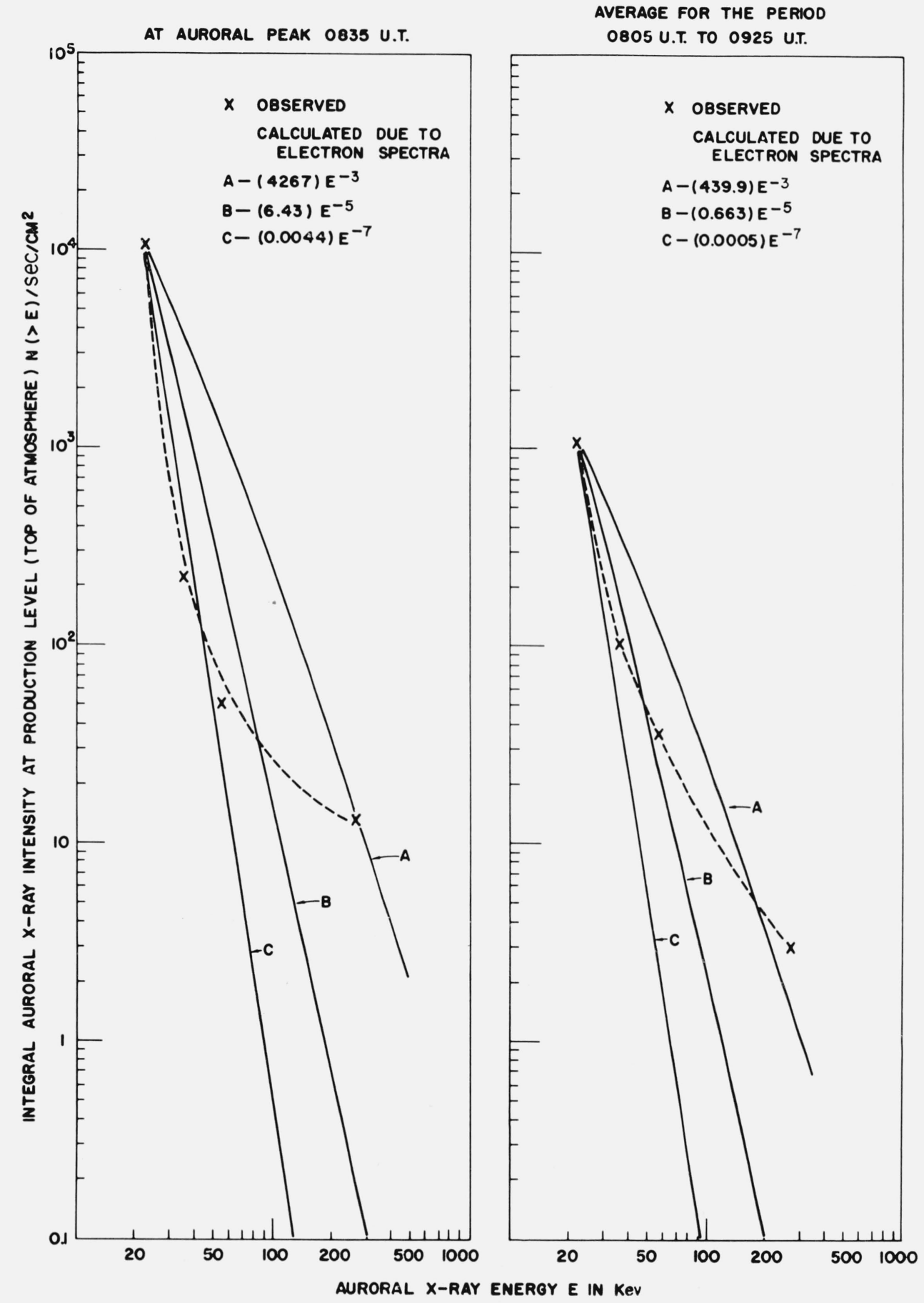

FIGURE 8. Trial spectra for dumped electrons during the May 1959 geomagnetic storm (Bhavsar [1961]).

Electron energies for the spectral formula at top of figure are in Mev. Observations are the crosses and dashed curves. by a simple power law electron spectrum. The scintillation counter results of Bhavsar on the aurora of May 12, 1959 show that a photon flux of $600 / \mathrm{cm}^{2} \cdot \mathrm{sec}$ greater than $22 \mathrm{kv}$ was measured at balloon heights of about $30 \mathrm{~km}$ or $10 \mathrm{~g} / \mathrm{cm}^{2}$ depth. The peak intensity of electrons precipitated on the top of the atmosphere of $E>22 \mathrm{kv}$ energy was $10^{9} / \mathrm{cm}^{2}$. sec. The 
average number over an 80 -min period which covered the intense part of the aurora $>22 \mathrm{kv}$ incident on the top of the atmosphere was $10^{12} / \mathrm{cm}^{2}$. The numbers given in table 1 from the work of May [1961], which have been derived assuming a power law spectrum with an exponent which gives the observed ratio of the counting rates of the instruments, give values between $10^{9} / \mathrm{cm}^{2}$ and $2 \times 10^{11} / \mathrm{cm}^{2}$ averaged over a typical electron burst of approximately 100 min duration. The spectra averaged over a period of bursts is probably the most satisfactory to use for further comparison. May [1961] has pointed out that the detailed structure of a burst shows variations in the spectra in a random manner as shown by large fluctuations in the ratio of the ion chamber and counters responding to the X-rays.

The X-ray bursts observed at geomagnetic latitude $55^{\circ}$ at Minneapolis may be summarized as follows.

(1) The bursts occur during strong bays or during the main phase of vigorous magnetic storms.

(2) Where visible auroral observations may be made, the X-ray bursts are correlated very well with aurorae at the zenith, particularly rayed structures. The time comparison is within the limit of accuracy of the measurements and may be as short as $1 \mathrm{~min}$.

(3) The X-ray bursts, the magnetic disturbances, and the aurora in general center during the night hours local time.

(4) The flux of electrons producing the X-ray bursts varies between $10^{9}$ and $10^{12}$ electrons $/ \mathrm{cm}^{2}$ during typical burst times of approximately $1 \mathrm{hr}$. The peak intensity may reach $10^{9} / \mathrm{cm}^{2} \cdot \mathrm{sec}$ in strong aurorae.

(5) The electron spectra which best fit the observed photons at balloon height are very steep and can be represented by a power law spectrum with exponent of 4 or 5 for the differential energy of the electrons.

\section{Auroral Zone X-ray Bursts}

Numerous observations have now been made, in the auroral zone of latitudes, of X-rays similar to those described above, at Fairbanks, Alaska, and Ft. Churchill, Manitoba. The earliest observation of what apparently is the same type of radiation now observed with balloons in the auroral zone was made by Van Allen [1957] using the "rockoon" sounding rocket technique. The rockoons frequently showed the presence above the atmosphere of much enhanced soft radiation. Van Allen identified this radiation as bremsstrahlung in a range of energy similar to the auroral X-rays. An example of such enhanced radiation above the atmosphere is given in figure 9 (from Van Allen's paper). The rockoon shots over a range of latitudes localized this sporadic radiation in the normal auroral region. However, the radiation was frequently not present on rocket soundings even in the auroral zone. The rockoon observations show that even at the time of sunspot minimum the bremsstrahlung high in the atmosphere could be observed. The typical fluxes observed by Van Allen and co-workers for the soft radiation above the atmosphere were found to be $10^{6}$ to $10^{8}$ electrons/

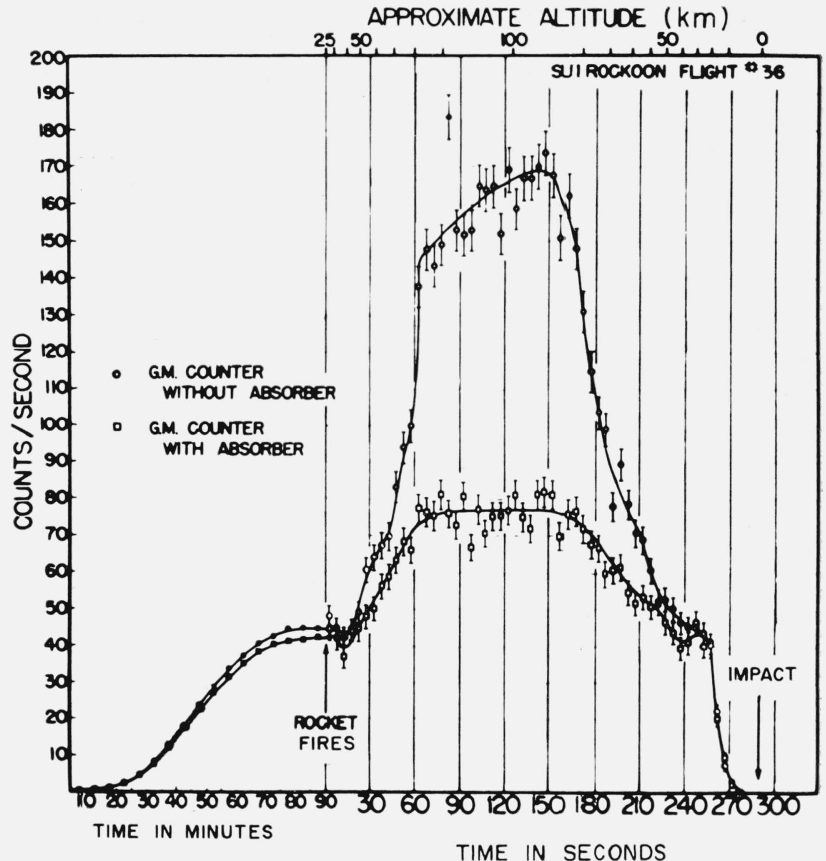

Figure 9. Time history and altitudes of a sounding rocket (rockoon) fired near the auroral zone (Van Allen [1957]).

This constitutes the first observation of what is probably an auroral zone $\mathrm{X}$-ray event of the type detected many times with balloons.

$\mathrm{cm}^{2} \cdot \mathrm{sec}$ for $E>10 \mathrm{kv}$, and the energy somewhat lower than is accessible to balloons. Van Allen called the bremsstrahlung "auroral radiation" but the direct association with visible aurorae was never made, due to daytime rockoon firings or cloudy skies. Later findings indicate that this rockoon soft radiation is probably not associated directly with aurorae.

The first observation of X-rays in the auroral zone with balloons was made by Anderson [1958] in August of 1957 at Ft. Churchill, geomagnetic latitude $69^{\circ}$. The soft radiation occurred during a considerable magnetic disturbance but was not definitely correlated with visible aurorae. Some variations were observed corresponding with changes in the earth's magnetic field; however, Anderson later applied scintillation detectors to the X-ray measurements in the auroral zone and has obtained many examples of bursts from which energy spectra could be derived. A good example of such bursts is shown in figure 10 during the August 17 to 18, 1959 geomagnetic disturbance. These measurements are of importance because the very elliptical orbit earth satellite Explorer VI was transmitting at this time and there was an opportunity to compare the intensity of the trapped radiation on lines of force connecting the satellite with the atmosphere at Ft. Churchill. This will be discussed below.

Figure 10 shows several features of the auroral zone bursts which seem to be typical. One of these is the appearance of the X-rays during both the day and night. The second is the results of the rates at different energy ranges which show that the spectrum is similar to that measured at lower latitudes 


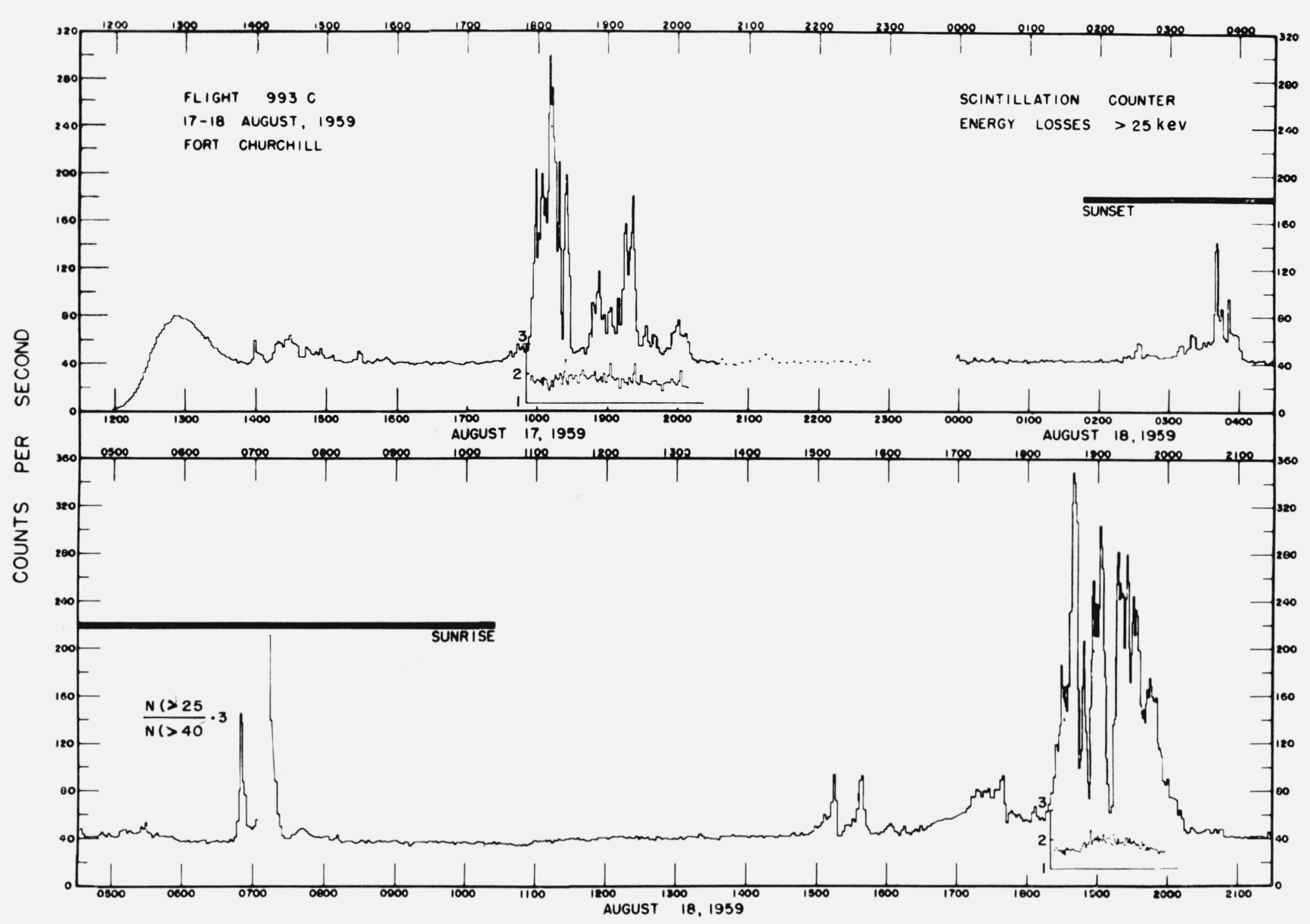

UNIVERSAL TIME

FIGURE 10. Counting rate of the scintillation detector due to energy losses greater than 25 kev during a very long balloon flight over Churchill.

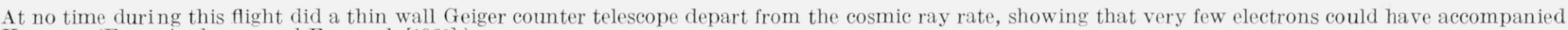
the X-rays. (From Anderson and Enemark [1960].)

described earlier. Detailed analysis [Anderson and Enemark, 1960] shows a very steep spectrum which can possibly be fitted by a power law but sometimes shows a flattening out at high energies. In a way similar to the lower latitude measurements, the individual bursts are of very short duration and appreciable variations in a time of about 1 sec can be found. Anderson has also shown that the auroral zone energetic X-rays are not coincident in time with visible aurorae. Figure 11 [Anderson and Enemark, 1960] compares the X-ray bursts with all-sky camera photographs which show that at the time of active forms at the zenith the X-rays were absent, but that the bursts occurred prior to the beginning of active forms. The well-known midnight maxima of aurorae in the auroral zone compared with the round-theclock occurrence of the energetic X-ray bursts also show the lack of association.

Recent rocket experiments by Mcllwain [1960] show dramatically the difference in energy of the particles causing the visible aurora in the auroral zone from energies measured in balloon X-rays. In figure 12 we reproduce two figures from McIlwain's paper which show the very high energy flux measured in a bright aurora in the form of electrons of $6 \mathrm{kv}$ or less, and at the same time no detectable effect on a Geiger counter of the type used in balloons. Although the Geiger counters at balloon height show, in general, small effects because of their low sensitivity, the rocket counter which went directly through the intense part of the aurora nevertheless is very significant in showing the absence of any bremsstrahlung above $20 \mathrm{kv}$. With fluxes as high as 5,000 ergs $/ \mathrm{cm}^{2}$.sec, which corresponds to electron fluxes $10^{12}$ to $10^{13} / \mathrm{cm}^{2}$ sec, the flux of electrons $>20 \mathrm{kv}$ must have been less than $10^{5} / \mathrm{cm}^{2}$.sec. Davis, Berg, and Meredith [1960] have also measured the flux of electrons and ions associated with aurora using rocket techniques at Fort Churchill in 1958. Davis' rocket firings did not penetrate directly through the intense region of an aurora, but detected electron fluxes in the range $8 \mathrm{kv}<E<100 \mathrm{kv}$ of 0.5 to $2.5 \mathrm{erg} / \mathrm{cm}^{2}$. sec-ster. These fluxes occurred in diffuse surfaces and post-breakup rayed structures of intensity $I$. Davis has also measured directly with rockets the electrons associated with auroral zone X-ray events 


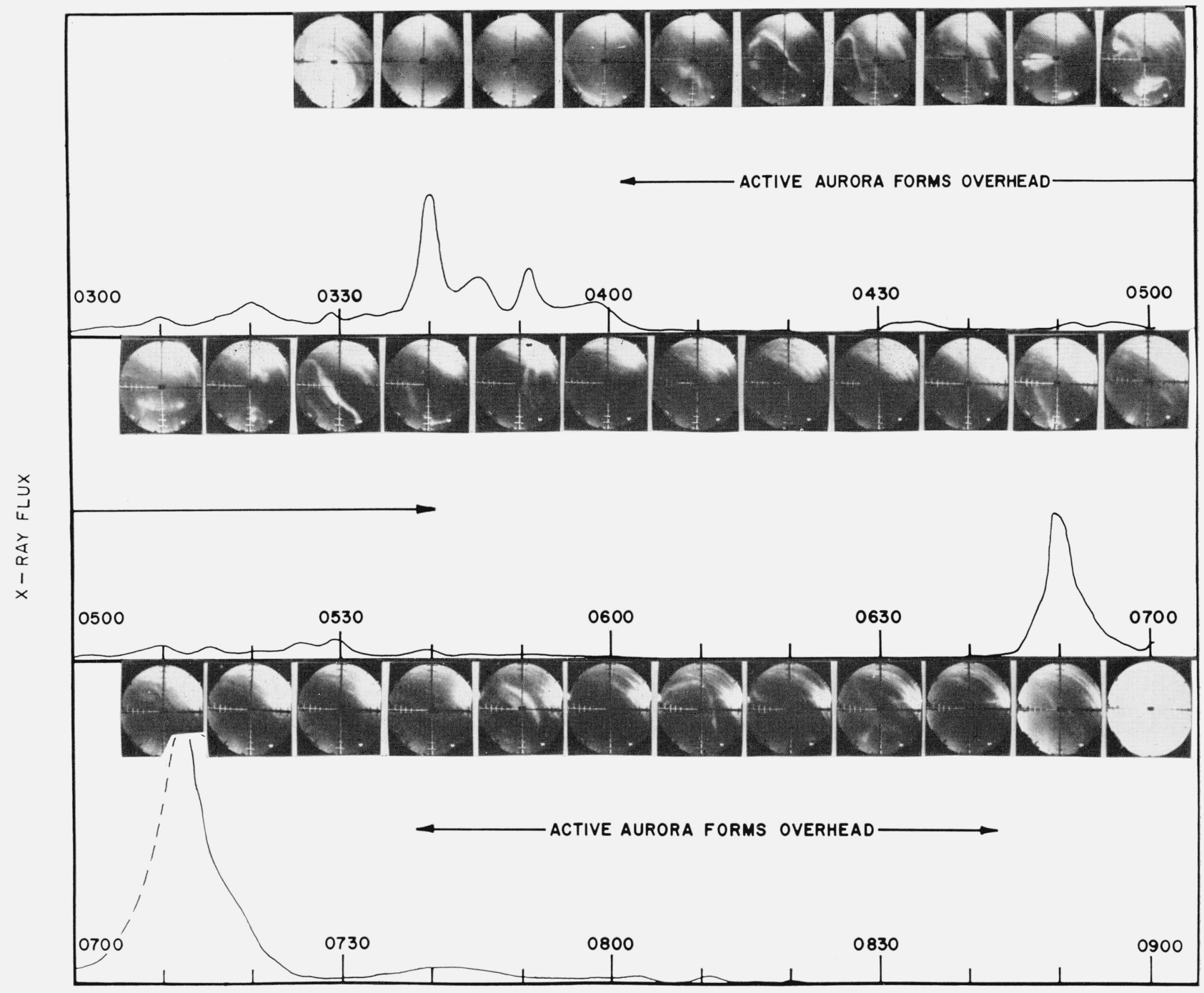

UNIVERSAL TIME 18 AUGUST 1959

Figure 11. Balloon X-ray record and all-sky camera photos.

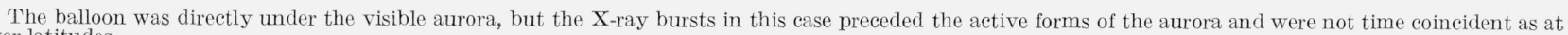
lower latitudes.

of the type detected with balloons. These measurements give important information about the precipitation process from the magnetic field and will be discussed later.

Some statistics concerning the X-rays and the electron spectra producing them from the work of Anderson from the Ft. Churchill observations, are as follows:

Electron spectra $\left.N(>E)=1.1 \times 10^{6} e^{-0.04 E}\right)$ Maximum of

Electron flux $>25 \mathrm{kv}=4 \times 10^{6} \mathrm{~cm}^{-2} \mathrm{sec}^{-1} \int_{\text {burst }}^{\text {bur }}$

Auroral zone X-rays present $40 \%$ of time.

$\mathrm{X}$-rays not closely correlated with magnetic conditions.

Daily flux into atmosphere $\sim 10^{10} / \mathrm{cm}^{2}$.
All of the balloon groups have reported at high latitude strong correlation between the X-ray bursts detected by the balloon instruments and the ionospheric absorption of radio waves, for example, by riometer measurements. "Auroral" absorption of extragalactic radio waves is frequently mentioned in the literature. However, the ionospheric effects with which we are interested are of a different type, are separated from the aurora, and are produced by relatively high energy electrons. In many cases the absorption follows in great detail the intensity of the X-rays observed at balloon heights. Figures 13 and 14 show comparisons of the $\mathrm{Ft}$. Churchill riometer (courtesy T. R. Hartz, Canadian Defence Research Board, Ottawa) and balloon ion chambers flown by the Minnesota group during the summer of 1960 . 

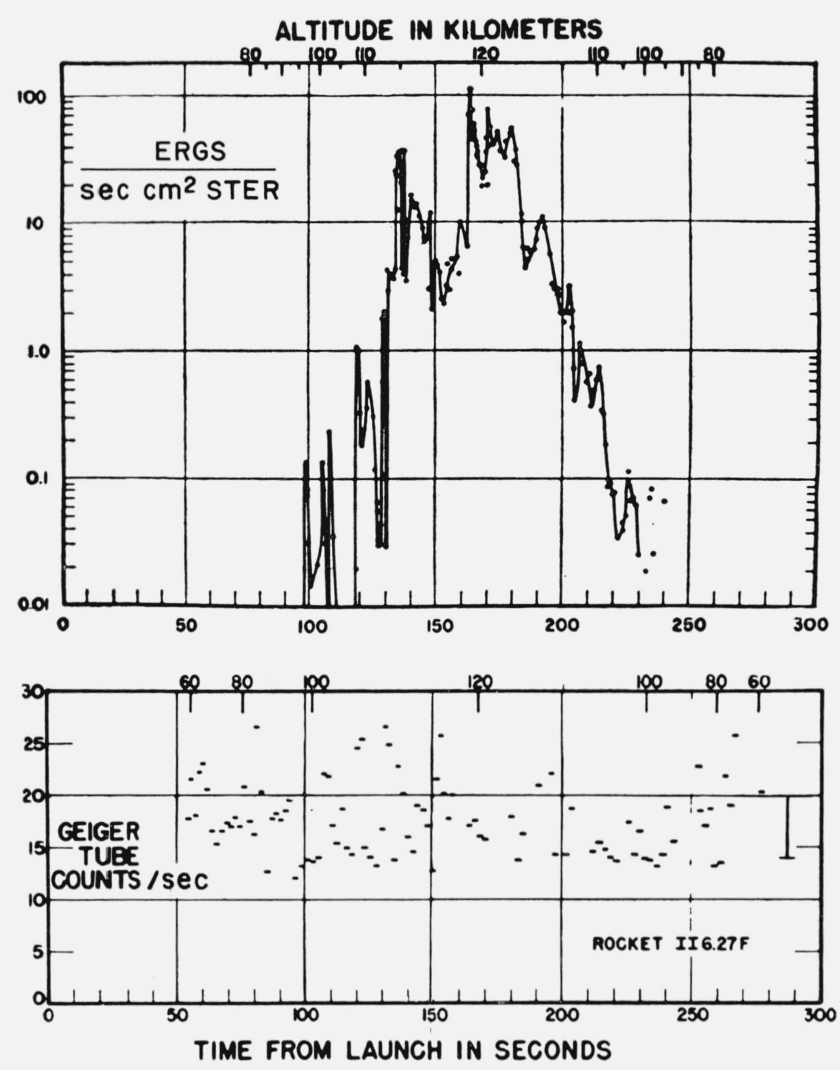

Figure 12. Total energy (upper) and Geiger counter rate (lower) during a rocket trajectory at Ft. Churchill which passed directly through a bright visible aurora. (From McIlwain [1960].)

Note the absence of any effect in the Geiger tube. The electrons were concentrated at approximately $6 \mathrm{kev}$.

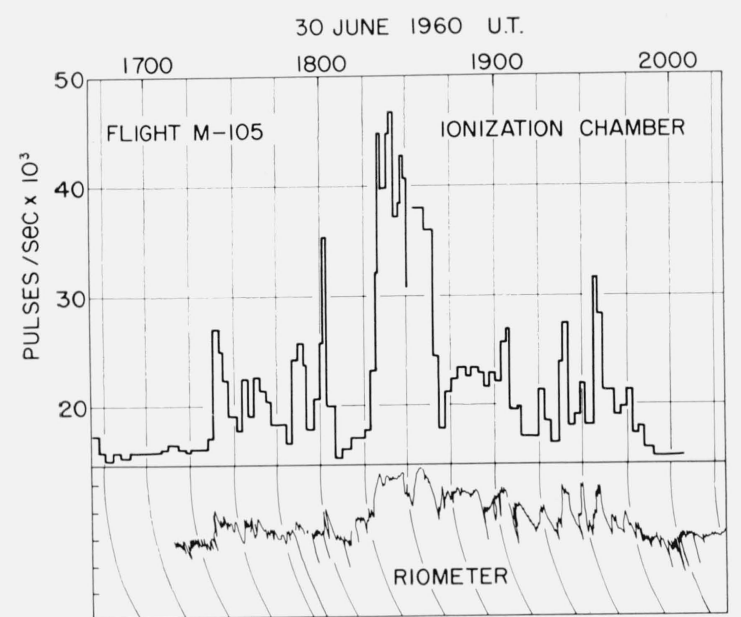

FIGURE 13. Ionization chamber record and riometer absorption at Ft. Churchill.

The ion chamber characteristics are described by May [1961]. The peak riometer absorption is several decibels.

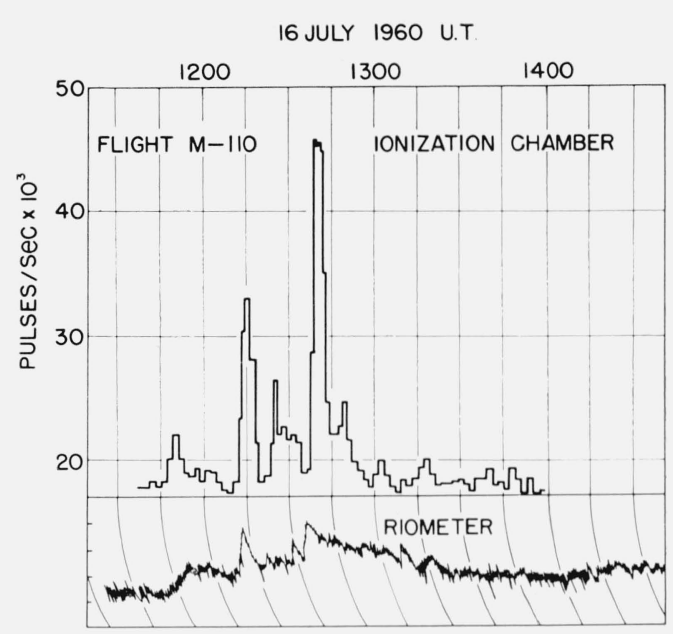

Figure 14. Another well-correlated case of balloon ion chamber and riometer at Ft. Churchill.

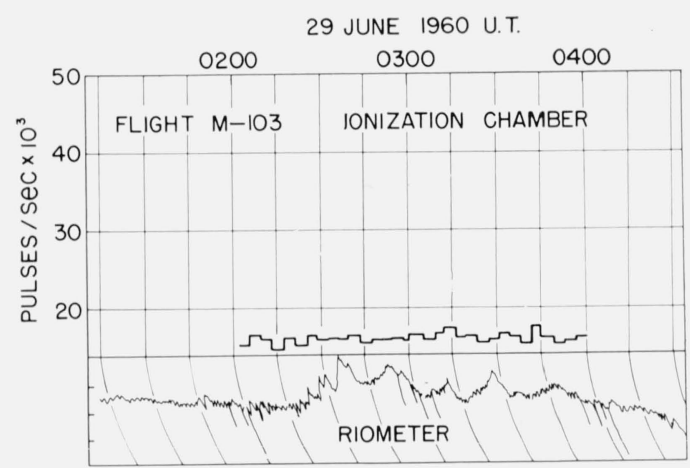

Figure 15. An example of a riometer event not seen by the balloon instruments.

It is believed that the local character of the event, and the difference in location of the balloon and riometer antenna pattern, produced this lack of correlation.

These cases show that the absorption event begins when the X-rays first appear, that the detailed ion chamber peaks are reflected in the riometer absorption increases, and that the high intensity bursts of X-rays correspond to large absorption. Figure 15 shows a case in which riometer absorption was detected but no disturbances at balloon height were observed. We believe that this poor correlation is due to the latitude and longitude drift of the balloon which carried it away from the region covered by the riometer antenna and that the precipitation was local enough in nature so that the correlation was destroyed. The auroral absorption seen on riometers has been discussed by Chapman and Little [1957]. In this paper the authors noted that the greatest absorption occurred during the pulsating period of the aurora and suggested that this absorption may have been connected with the X-rays discovered at balloon altitudes. We have made the argument [Winckler, Peterson, Hoffman, and Arnoldy, 1959] that, since the primary electrons carry $10^{3}$ to $10^{4}$ times the energy carried by the X-rays, the absorption was likely caused by the primary electrons 
themselves even though they do not penetrate very much into the $D$-layer of the ionosphere. However, the riometer absorption probably does not occur above heights of $70 \mathrm{~km}$. If this is true, it is difficult to see how the primary electrons can penetrate this far into the atmosphere and cause the absorption.

Recently, Brown, Hartz, Landmark, Leinbach, and Ortner [1961] have shown the widespread correlation between a balloon X-ray burst detected by balloons at Fairbanks, Alaska, at the time of sudden commencement of a magnetic storm and riometers distributed over the auroral region including stations in Norway and Sweden. The correlated absorption increase of several decibels occurred during auroral activity at many of the stations but was detectable because it was a sharp, isolated absorption maximum lasting only a few minutes. The precipitation of the electrons occurred only in a ring or a series of patches around the auroral zone and not over the complete polar cap. A few cases are available in which such X-ray events were studied by balloons at several locations simultaneously, for example the July $16-18,1960$ event. It is evident that more correlation is obtained between balloons at high latitudes near the auroral zone than between the auroral zone and southerly latitudes at Minneapolis. In fact, in most instances during X-ray bursts observed at Churchill, no correlation at all is obtained with bursts at Minneapolis. Similarly, there are good cases on record in which the precipitation of strong X-ray bursts at Minneapolis is not accompanied by any detectable effect at higher latitude. For example, on September 3, 1960, a strong X-ray burst was recorded at 0111 UT only at Minneapolis [Winckler, Bhavsar, Masley, and May, 1961].

Estimates have been made of the electron fluxes in the auroral zone causing the bursts there and in general these estimates show a smaller flux than at lower latitudes. For example, the event studied by Brown, Hartz, Landmark, Leinbach, and Ortner [1961] described above corresponds to a flux of 2 to $6 \times 10^{7}$ electrons $/ \mathrm{cm}^{2} \cdot \mathrm{sec}$ with energies $>50 \mathrm{kv}$. The total integrated electron intensity was 3 to $9 \times 10^{9}$ electrons with energy $>50 \mathrm{kv}$ per $\mathrm{cm}^{2}$. Brown [1961] finds that at Fairbanks, Alaska, during June and July 1960, the auroral zone X-rays are detectable with Geiger counters apppoximately 10 percent of the time at pressure altitudes in the range 10 to $15 \mathrm{mb}$. The darly flux of electrons with energies $>50$ $\mathrm{kv}$ is about $6 \times 10^{10}$ particles $/ \mathrm{cm}^{2}$. On August 16 , 1959, Anderson and Enemark [1960] found a peak flux of primary electrons $>25 \mathrm{kv}$ of $4 \times 10^{6}$ on a vigorous event. The maximum photon flux accompanying such bursts was 40 photons $/ \mathrm{cm}^{2}$.sec above $22 \mathrm{kv}$. However, Anderson also concludes that the influx of electrons occurs a much greater proportion of the time in the auroral zone than at Minneapolis. These estimates show that an average flux of 10 photons $/ \mathrm{cm}^{2}$.sec may be present as much as 40 percent of the time and that these measurements are conservative. Thus, although the peak intensities are much lower as can be seen by comparing these figures with the fluxes mentioned above at the latitude of Minneapolis, the larger number of the bursts of all sizes still brings the total number of electrons precipitated to quite a high value. Anderson estimates that the daily flux of electrons above $25 \mathrm{kv}$ energv lost in the atmosphere over the auroral zone is of the order of $10^{10} / \mathrm{cm}^{2}$. Similar observations were obtained by the Minnesota group in flights made at Ft. Churchill during the summer of 1960 when the sporadic X-ray bursts were observed on many occasions. The correlation with the riometer shown in figures 13 and 14 are examples of these bursts. The mean energies are similar to bursts observed at Minneapolis with the same instruments, but in general, the intensities are less.

In summary, the characteristics of the X-rays observed in the auroral zone are that they occur a considerable fraction of the time at low intensity, that enhanced intensity occurs during geomagnetically disturbed periods, that the peak intensity of the bursts is much lower than at lower latitudes, that the bursts are not closely associated with visible aurorae, and that in the auroral zone at certain times widespread close time correlations are observed in the precipitation of the electrons but that sometimes also the precipitation at high latitude and that at intermediate latitude are apparently not correlated in time in any detail.

The discovery of the trapped radiation belts around the earth has resulted in a fresh and very promising approach for understanding the phenomena of the aurora. It is the opinion of the writer that the precipitation of the electrons producing the balloon X-ray events may have a similar close connection with the trapped radiation. In this case the possibility of discovering relationships is even better than for the visual aurora, since the energy range of the electrons producing the balloon X-rays is similar to that of the trapped electrons which have been measured with counting devices in satellites and space probes. The presence of a large reservoir of radiation contained in the magnetic field a short distance above the atmosphere may provide a source for the electrons seen entering the atmosphere, and a search should be made for suitable perturbation mechanisms by which the trapped electrons may be discharged into the atmosphere at a time of magnetic disturbances.

It should first be pointed out that the general appearance of the energy spectrum of the precipitated electrons deduced from the balloon observations is similar to the spectrum of electrons in the outer zone of the Van Allen regions which has been obtained from rocket and satellite measurements. The differential spectrum deduced from the balloon measurements has the form $\mathrm{CE}^{-6}$. According to Vernov and Chudakov [1960], the spectrum in the high intensity region of the outer radiation zone can be represented by a similar spectrum $\mathrm{CE}^{-5}$. Of course, this similarity of spectra is no proof in itself that the precipitated electrons actually are a part of the trapped reservoir. However, there are other relationships which support this view. We show in 
figure 16 a profile of the outer radiation zone along a radius in the equatorial plane. These data were obtained from the satellite Explorer VI with the University of Minnesota Geiger counter unit [Arnoldy, Hoffman, and Winckler, 1960a]. The two curves are for two periods representing the first week of Explorer VI during a quiet period, and the higher curve during an enhanced period following a strong geomagnetic disturbance. Also shown in figure 16 are the dipole lines of force which show the connection with the earth's surface in geomagnetic latitude. We see that a line of force intercepting Ft. Churchill or Fairbanks, Alaska, reaches the equator between 40,000 and $50,000 \mathrm{~km}$ from earth center. In this region there is an appreciable intensity of trapped electrons of $50-\mathrm{kv}$ mean energy. During the quiet period, August 7 to 14, 1959, as shown in the lower curve in figure 16, the intensity on the Ft. Churchill Jine of force, however, was near the cosmic ray background which, in this figure, was about two counts per second. About an order of magnitude more counting rate was observed during the enhanced perind from August 24 to 30 . If we consider a line of force which connects with the latitude of Minneapolis at about $55^{\circ}$, we find that this connects in the radiation belt just at the region of most intense trapped radiation in the equatorial plane. During the history of Explorer VI, the outer zone exhibited a complicated structure, frequently having two maxima which are well illustrated in figure 16. It was observed that the outer of these two maxima was the most strongly modulated by the geomagnetic disturbances. In this region of the radiation belts the intensity is some 1,000 times greater than in the region connecting with the surface in the auroral zone. It appears to be not mere chance that the peak intensity of the X-ray bursts observed at Minneapolis is considerably larger than the peak intensity of bursts observed in the auroral zone region, and that this fact implies that the trapped radiation may, in fact, constitute the reservoir from which the balloon X-ray events are produced.

Another interesting feature of the outer radiation belt is shown in figure 17 . This figure derived by Van Allen and co-workers (private communication) from the satellite Explorer VII shows the location of the maximum of the outer radiation belt at heights of about $100 \mathrm{~km}$. The satellite passed through the lower edge of the trapping region at $1,000 \mathrm{~km}$ and the position at this altitude is then projected downward along a local magnetic line of force to the altitude of $100 \mathrm{~km}$ where discharged radiation would enter the dense atmosphere. Each point represents a value so obtained at $100 \mathrm{~km}$ from a pass of the satellite. The curved lines on the map labeled

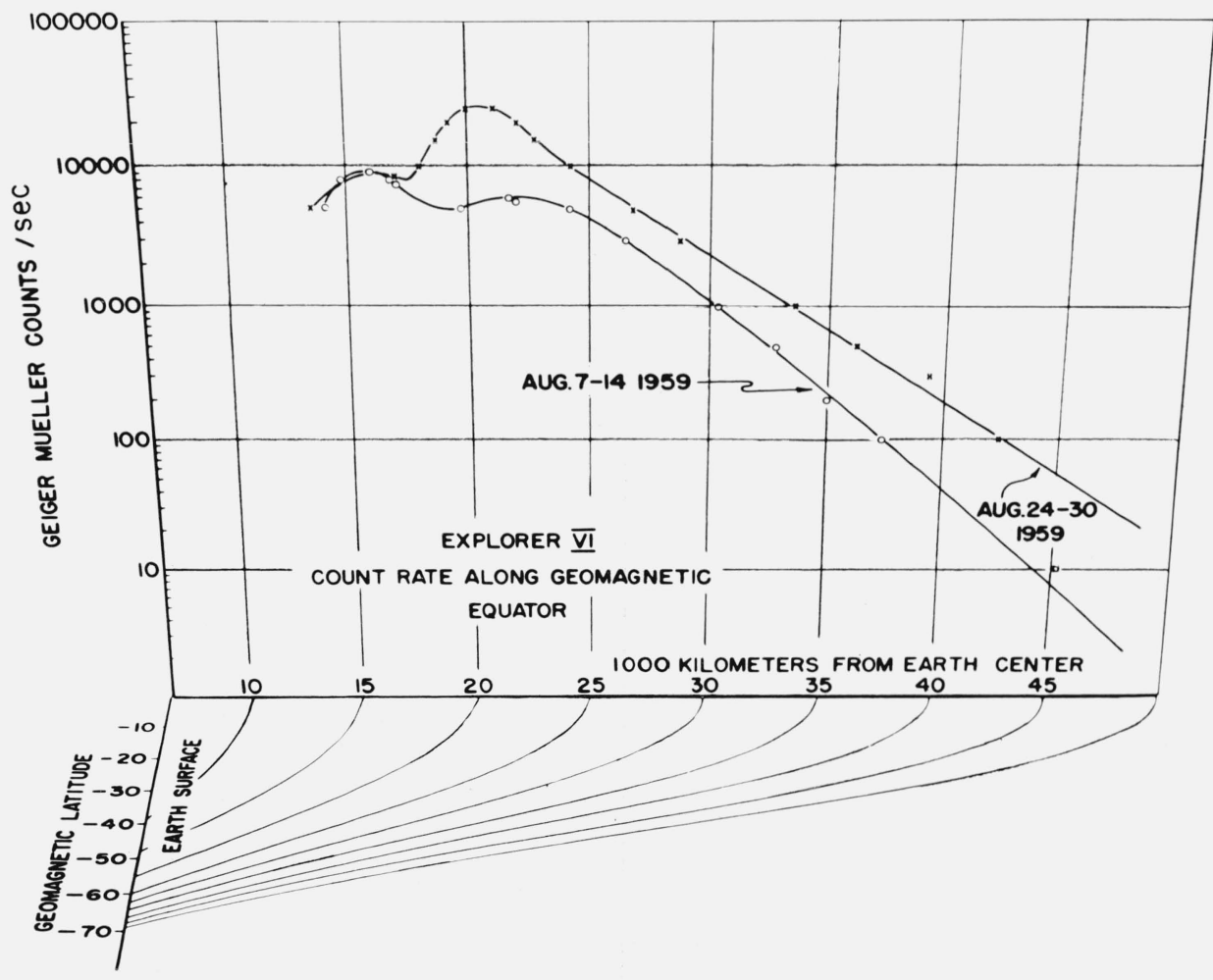

Figure 16. Profile of the outer Van Allen region along a radius in the magnetic equatorial plane measured by the Geiger counter on Explorer VI.

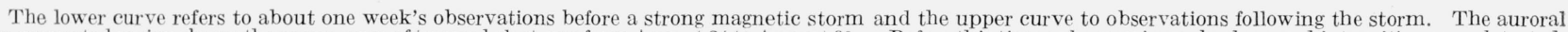

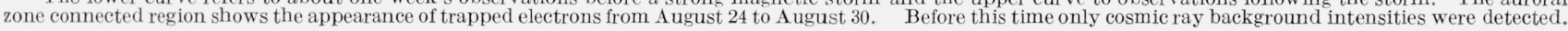




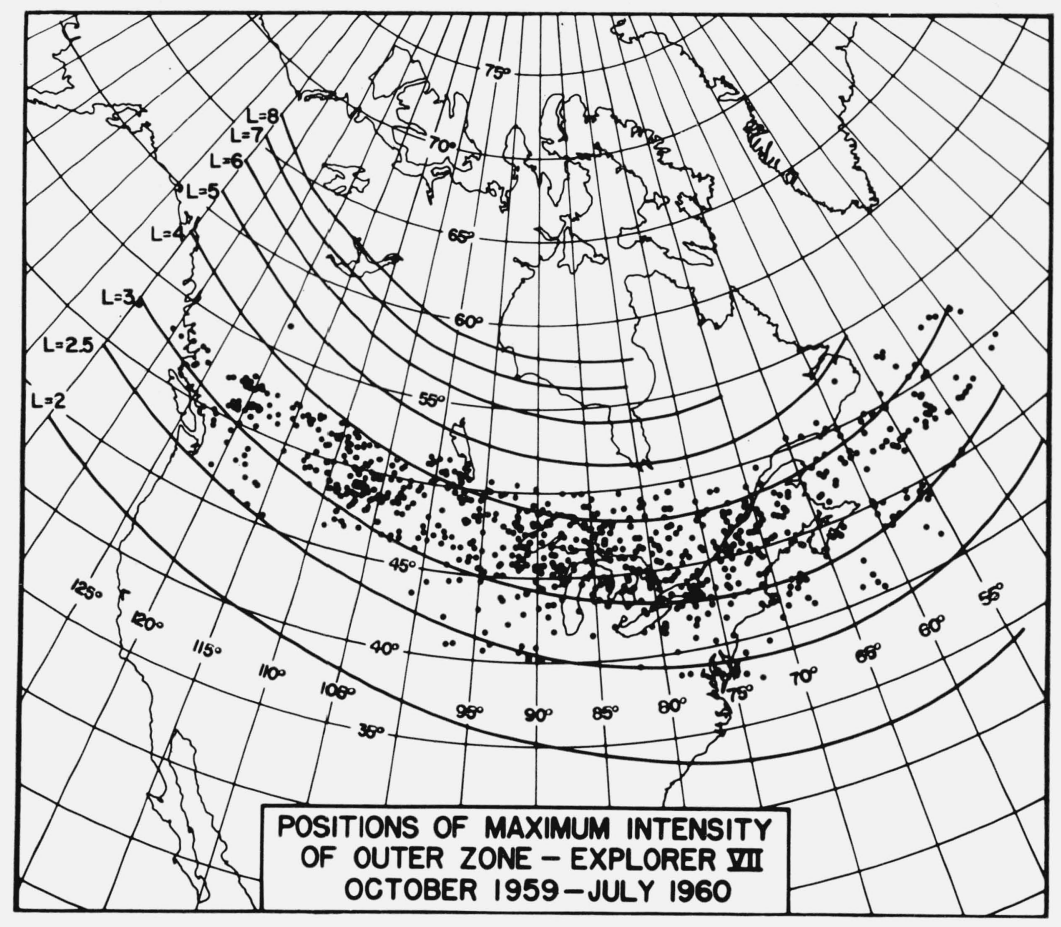

FIgURE 17. The outer zone maximum at $100 \mathrm{~km}$ from Explorer VII (Van Allen, private communication) measured at $100 \mathrm{~km}$ and projected downward along field lines.

Note that Minneapolis lies directly under this maximum zone.

with $L$ numbers from 2 to 8 represent guiding center shells and the $L$ value refers to the radius in the equatorial plane where this shell crosses. We see that the outer zone locus conforms well to the shape of this pattern of shells derived from the well-known properties of the electrons trapped in the geomagnetic field. It should be noted also that the center of this region is about $1^{\circ}$ in latitude north of Minneapolis and is located between 56 and $57^{\circ}$ geomagnetic. Figures 16 and 17 are quite consistent in their implications although they were measured over considerably different periods of time. The balloon measurements of auroral zone X-rays made by Anderson on August 17 and 18, 1959, shown in figure 10, are especially significant as Explorer VI was making passes through the magnetic shell connecting to Ft. Churchill, the balloon location. This region of the radiation belts normally gave only cosmic ray background rates on the Anton type 302 counter in Explorer VI [Arnoldy, Hoffman, and Winckler, 1960a]. On August 17 a significant intensity of trapped electrons appeared in this region giving a rate in space from bremsstrahlung of about 20 to 40 $\mathrm{c} / \mathrm{s}$ and showing much structure between 48,000 and $32,000 \mathrm{~km}$. The intensity in this far edge of the outer zone remained high until September 4 . This is shown also in figure 16 (enhanced curve). The $\mathrm{X}$-ray bursts at Ft. Cburchill during this time were exceptionally intense for auroral zone bursts.

Early in this storm on August 16 the Anton 302 counting rate in the main outer zone showed a substantial decrease [Arnoldy, Hoffman, and Winckler, 1960a]. This was interpreted as a dumping process. The loss of energetic radiation was contained in lines of force reaching to the latitude of Minneapolis, where a strong aurora was observed. Aurorae of this type, with corona and rayed structure at the zenith, invariably accompany X-ray bursts in cases where balloon observations are available. The dumping, however, must accompany redistribution and energy changes of the trapped radiation. Sufficient radiation apparently disappeared from the trapping region on this occasion to have accounted for a strong balloon X-ray event.

An explanation of the X-ray phenomena in terms of the trapped radiation and processes in the geomagnetic field, of course, excludes the possibility that the balloon $\mathrm{X}$-ray electrons are injected directly from solar streams. So far, only one conclusive case exists in which it can be shown that such solar injection does not occur. This was during the history of the deep space probe Pioneer V [Arnoldy, Hoffman, and Winckler, 1960b] when it was shown that by comparison with the earth satellite Explorer VII [Van Allen and Ching Lin, 1960] large changes in the outer radiation belt occurred when the electron flux in deep space was negligibly small. We will assume that the observation on this one event on March 31, 1960 is typical of other cases and, in fact, that it is unreasonable in any case that the $50-\mathrm{kv}$ electrons would be able to find their way from the sun and be injected into the earth's field in a manner sufficient to produce the observed trapped radiation. In fact, the whole auroral phenomenon and the X-ray 
observations become much easier of understanding if one assumes that they are caused by particles which constitute the trapped radiation surrounding the earth. For example, the continual precipitation of small fluxes of X-rays in the auroral zone occurs from a part of the earth's field which is at a large distance, where the field is weak and solar plasma streams can frequently and easily perturb the field. On the other hand, the precipitation of electrons from the heart of the outer zone, which is at a much smaller distance from the earth's center, can only occur during violent magnetic distrubances, but then one might expect much larger peak fluxes of electrons and X-rays. It has been clearly demonstrated in the first section of this paper that this is the manner in which the balloon X-rays are actually observed to occur.

However, the process of the precipitation of electrons from the magnetosphere into the dense atmosphere at $100 \mathrm{~km}$ cannot be merely a simple ejection from a static reservoir. In order to bring electrons out of the field, acceleration, deceleration, and redistribution of the entire spectrum of electrons present in the trapped radiation must occur. A crude spectrum of electrons which may participate in these processes during perturbation of the field is given in figure 18. These densities are those estimated for the upper ionosphere, whistler phenomena, visible aurorae, and the trapped radiation studied with counters in satellites. The portion of the spectrum measured in the balloon X-ray and satellite experiments lies mainly between 10 and $100 \mathrm{kv}$.

If an X-ray observation shows a certain flux of electrons entering the atmosphere at the foot of a Jine of force, then these electrons at some point along their guiding center trajectory must enter the "dumping" cone of pitch-angle directions. This cone of directions is defined by

$$
\frac{\sin ^{2} \psi_{m}}{B}=\frac{1}{B_{1}}
$$

where $\psi_{m}$ is the angle to the local field direction at a point on the line of force of field intensity $B, B_{1}$ is the field intensity on the same line of force at a height $h$ where the electrons are removed by atmospheric scattering. This height may lie between 100 and $300 \mathrm{~km}$, and $\psi=90^{\circ}$ in this region. At the equator on a trajectory or shell connecting to Minneapolis the dumping cone half-angle collapses to about $7^{\circ}$. Under "quiescent" conditions the dumping cone should be empty of particles. Any process which injects particles into the dumping cone at any position along a line of force may cause precipitation. Such processes might be betatron type acceleration or deceleration, scattering by hydromagnetic waves, or perturbation by VLF electromagnetic waves especially if the frequency is near the gyrofrequency of the electrons. Multiple coulomb scattering, even during periods when the scale height of the atmosphere increases during storms, cannot be a primary mechanism for producing the intense, rapid and sporadic balloon X-rays. On a line of force connecting to the auroral zone the dumping cone col-

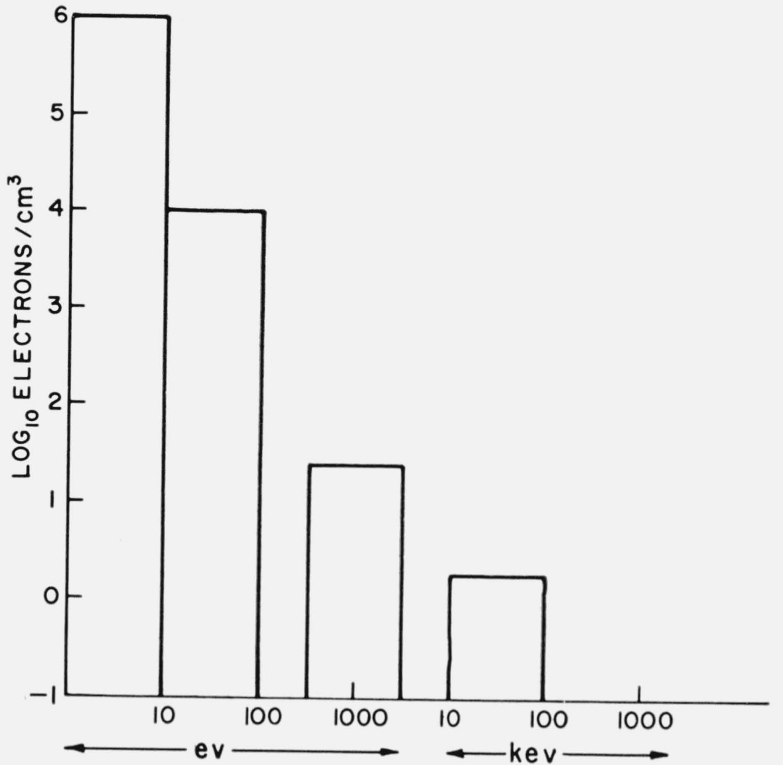

Figure 18. Estimate of relative concentration of electrons of various energies trapped in the geomagnetic field.

lapses to a much smaller angle, approximately $3^{\circ}$ at the equator.

Thus both the volume in velocity space and the surrounding flux of electrons which may enter this volume are larger for Minneapolis than for the auroral zone.

Electrons in the dumping cone were observed in a striking manner by the rocket observations of Davis, Berg, and Meredith [1960]. Figure 19 reproduces preliminary electron distributions at $100 \mathrm{~km}$ above Ft. Churchill on June 6, 1960, at 1110 U'T. It can be seen that as the intensity of electrons increases, the angular distribution changes from a flat form with maximum intensity at $\psi=70^{\circ}$ to a form with direction between $\psi=0$ and $\psi=70$ filled in by trajectories.

Since the dynamics of the outer Van Allen belt presents such a complex problem, in this paper only certain requirements to be met by a "dumping", mechanism will be stated, and some suggestions made for mechanisms to accomplish this.

The requirements are:

(1) The frequent discharge into the auroral zone atmosphere of electrons from a region or shell crossing the geomagnetic equator at 6 to 7 earth radii. The discharge must occur in both the sunlit and dark hemispheres. It may be intensified at times of magnetic disturbances but must also occur during "quiet" periods as shown by surface magnetometers.

(2) At times (e.g., at a sudden commencement) the auroral zone dumping must occur simultaneously over a wide range of longitudes. At other times the dumping may be local.

(3) The integrated 24-hr flux of electrons dumped from the far reaches of the geomagnetic field may equal or exceed the total trapped flux in that region. Thus the store of electrons in a lower energy region 


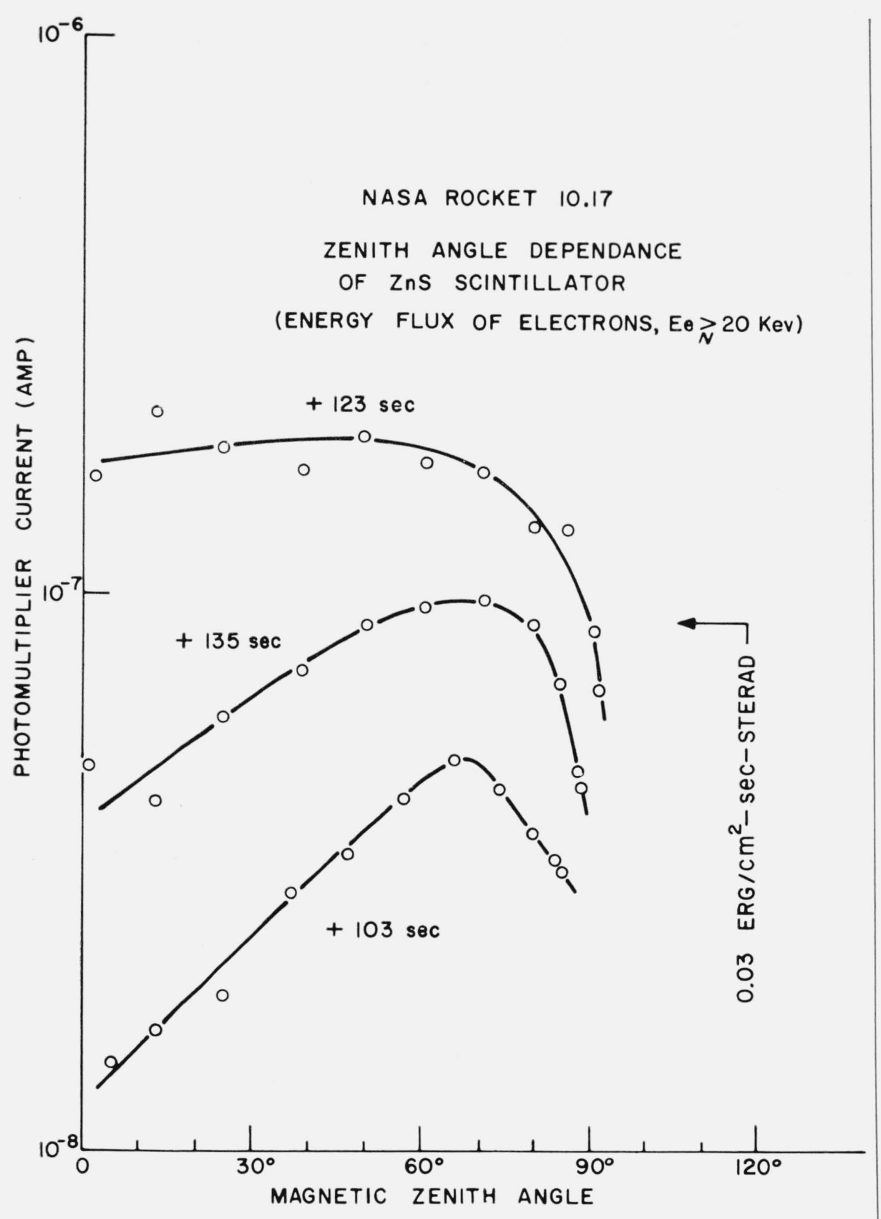

FIGURE 19. Angular distribution of electrons showing dumping during an intensity increase observed near $100 \mathrm{~km}$ altitude at Ft. Churchill by Davis (private communication) in 1960.

Note that the intensity increase shows much more strongly for directions along the magnetic field. These electrons are emerging from the "dumping cone" near the magnetic field. These electrons are emerging from the
the atmosphere. Time of firing: 1110 UT on June $6,1960$.

shown in figure 18 must be utilized through a local acceleration mechanism. Direct injection from solar clouds does not seem likely.

(4) The dumping mechanism must operate selectively for the high latitude, high energy electrons so that strong time correlations with the dumping of low energy visible auroral radiation are not obtained.

(5) In the case of strong low latitude auroral and magnetic storms, dumping must occur from the heart of the outer zone at about 3.5 earth radii. In this case it is probable that all energies of auroral particles including balloon X-ray electrons appear in the atmosphere simultaneously.

(6) Low latitude dumping must be time-correlated with local negative magnetic bays.

(7) The peak dumped electron flux at approximately $50 \mathrm{kv}$ must at times reach $10^{9}$ electrons/ $\mathrm{cm}^{2}$.sec at low latitudes. In the auroral zone the peak flux must be $10^{6} / \mathrm{cm}^{2} \cdot$ sec.

Several classes of phenomena may be considered with dumping as one of the consequences. Slow changes in the magnetic field with characteristic times from many minutes to days may involve major distortions of the dipole field. In such cases betatron processes may alter the energy spectrum and redistribute the trapped radiation. During betatron processes the invariants of motion in a fixed field may not be preserved and redistribution of the radial profile of trapped radiation may result. Thus it is conceivable that either acceleration or deceleration accompanied by migration of electrons radially inward or outward may occur and cause injection into the dumping cone. The mixing of tubes of force has been suggested by Gold (presented to URSI meeting Mav 1, 1961, Washington, D.C.) as a means for redistributing the low energy trapped radiation. The effect on high energy trapped electrons is not known, but may be small. This kind of mechanism may be able to provide a selective dumping of auroral particles and X-ray electrons at high latitudes.

Rapid changes in the magnetic field in the frequency range of $1 \mathrm{c} / \mathrm{s}$ to $50 \mathrm{kc} / \mathrm{s}$ seem a very promising mechanism. Powerful scattering may occur if hydromagnetic or VLF frequencies approach the cyclotron frequency of the trapped electrons. Measurements of micropulsations during magnetic storms have been made by many observers. Recently K. A. Anderson (private communication) has shown that the auroral zone X-rays occur in close time correlation with periodic micropulsations in the 1 c/s range. VLF emissions observed by Gallet (private communication) also seem correlated in a general way with the appearance of electron precipitation, particularly the type of emission known as narrow band hiss. Such emissions may occur near the cyclotron frequency for electrons at large distance in the geomagnetic field.

Recently Akasofu and Chapman [1961] have proposed a neutral line theory to account for specific features of the visual aurora. They have not applied their ideas to the dumping of energetic electrons. The lack of correlation between auroral zone X-rays and auroral zone visual aurorae presents some difficulties for understanding the energetic electron phenomena on the basis of their ideas.

The lowering of mirror points by solar stream distortion of the geomagnetic field has been proposed by Kern and Vestine [1961] to account for the nighttime polar electrojet. Because the X-ray production has no strong nighttime dependence in the auroral zone this mechanism may not be applicable. However, the preferential nighttime dumping at Minneapolis must in some indirect way be related to such an asymmetry with respect to the solar direction. Other mechanisms involving electrostatic forces specifically for dumping auroral particles have been suggested by Chamberlain [1961] and Kern [1961].

\section{References}

Akasofu, Syun-Ichi, and Sydney Chapman, The ring current, geomagnetic disturbance, and the Van Allen radiation belts, J. Geophys. Research 66, 1321-1350 (1961).

Anderson, K. A., Soft radiation events at high altitude during the magnetic storm of August 29-30, 1957, Phys. Rev. 111, 1397-1405 (1958). 
Anderson, K. A., and D. C. Enemark, Balloon observations of X-rays in the Auroral Zone II, J. Geophys. Research 65, 3521-3538 (1960).

Arnoldy, R. L., R. A. Hoffman, and J. R. Winckler, Observations of the Van Allen radiation regions during August and September 1959, Part I, J. Geophys. Research 65, 13611376 (1960a).

Arnoldy, R. L., R. A. Hoffman, and J. R. Winckler, Solar cosmic rays and soft radiation observed at $5,000,000$ kilometers from earth, J. Geophys. Research 65, 3004-3007 (1960b).

Bhavsar, P. D., Scintillation counter observations of auroral X-rays during the geomagnetic storm of May 12, 1959 , J. Geophys. Research 66, 679-692 (1961).

Bless, R. C., C. W. Gartlein, D. S. Kimball, and G. Sprague, Auroras, magnetic bays, and protons, J. Geophys. Research 64, 945-953 (1959).

Brown, R. R., Balloon observations of auroral-zone X-rays, J. Geophys. Research 66, 1379-1388 (1961).

Brown, R. R., T. R. Hartz, B. Landmark, H. Leinbach, and J. Ortner, Large-scale electron bombardment of the atmosphere at the sudden commencement of a geomagnetic storm, J. Geophys. Research 66, 1035-1041 (1961).

Chamberlain, J. W., Theory of auroral bombardment, to be published in Astrophys. J. (Sept. 1961).

Chapman, S., and C. G. Little, The nondeviative absorption of high-frequency radio waves in auroral latitudes, J. Atmospheric and Terrest. Phys. 10, 20-31 (1957).

Davis, L. R., O. E. Berg, and L. H. Meredith, Direct measurements of particle fluxes in and near auroras, Space Research: Proc. of the First International Space Science symposium, Nice, 1960, ed. H. K. Kallmann Bijl, N. Holland Publishing Co., Amsterdam, pp. 721-735 (1960).

Kern, J. W., Geomagnetic field distortion by a solar stream as a mechanism for the production of polar aurora and electrojets, Report RM-2753-NASA. The Rand Corp., Santa Monica (1961)
Kern, J. W., and E. H. Vestine, Theory of auroral morphology, J. Geophys. Research 66, 713-724 (1961).

May, Thomas C., A study of auroral X-rays at Minneapolis between 23 August 1959 and 1 August 1960, Cosmic Ray Technical Report No. CR-36, School of Physics, University of Minnesota, Minneapolis (March 1961).

McIlwain, Carl E., Direct measurement of particles producing visible auroras, J. Geophys, Research 65, 2727-2747 (1960).

Van Allen, James A., Direct detection of auroral radiation with rocket equipment, Proc. of the NAS 43, 57-62 (1957).

Van Allen, James A., and Wei Ching Lin, Outer radiation belt and solar proton observations with Explorer VII during March-April 1960, J. Geophys. Research 65, 2998-3003 (1960)

Vernov, S. N., and A. E. Chudakov, Terrestrial corpuscular radiation and cosmic rays, Space Research: Proc. of the First International Space Science Symp., Nice, 1960, ed. H. K. Kallmann Bijl, N. Holland Publishing Co., Amsterdam, pp. 751-796 (1960).

Winckler, J. R, Balloon study of high-altitude radiations during the International Geophysical Year, J. Geophys. Research 65, 1331-1259 (1960).

Winckler, J. R., and P. D. Bhavsar, Low energy solar cosmic rays and the geomagnetic storm of May 12, 1959, J. Geophys. Research 65, 2637-2655 (1960).

Winckler, J. R., P. D. Bhavsar, A. J. Masley, and T. C. May, Delayed propagation of solar cosmic rays on 3 September 1960, Phys. Rev. Ltrs. 6, 488-491 (1961).

Winckler, J. R., P. D. Bhavsar, and L. E. Peterson, The time variations of solar cosmic rays during July 1959 at Minneapolis, J. Geophys. Research 66, 995-1022 (1961).

Winckler, J. R., L. Peterson, R. Hoffman, and R. Arnoldy, Auroral X-rays, cosmic rays and related phenomena during the storm of February 10-11, 1958, J. Geophys. Research 64, 597-610 (1959).

(Paper 66D2-180) 